\title{
Consistency of dimensional distributions and refractive indices of desert dust measured over Lampedusa with IASI radiances
}

\author{
Giuliano Liuzzi $^{1}$, Guido Masiello ${ }^{1}$, Carmine Serio ${ }^{1}$, Daniela Meloni ${ }^{2}$, Claudia Di Biagio ${ }^{3}$, and Paola Formenti ${ }^{3}$ \\ ${ }^{1}$ School of Engineering, University of Basilicata, Via dell'Ateneo Lucano 10, Potenza, Italy \\ ${ }^{2}$ ENEA, Laboratory for Observations and Analyses of the Earth and Climate, Via Anguillarese 301, Rome, Italy \\ ${ }^{3}$ Laboratoire Interuniversitaire des Systémes Atmosphériques (LISA), UMR-CNRS 7583, Créteil, France
}

Correspondence to: Giuliano Liuzzi (giuliano.liuzzi@unibas.it)

Received: 29 July 2016 - Discussion started: 14 September 2016

Revised: 18 January 2017 - Accepted: 27 January 2017 - Published: 23 February 2017

\begin{abstract}
In the context of the ChArMEx campaign, we present here some results concerning the quantitative comparison between simulated and observed radiances in the presence of atmospheric desert dust, between June and July 2013 in the southern Mediterranean Basin, in the air mass above the island of Lampedusa. In particular, comparisons have been performed between radiances as observed by the Infrared Atmospheric Sounder Interferometer (IASI) and those simulated using the $\sigma$-IASI-as radiative transfer model, which takes into account aerosol extinction effect through a set of fast parameterizations. Simulations have been carried out using different sets of input complex refractive indices, which take into account the parent soils of the aerosols. Their accuracy also relies on the quality of the characterization of desert dust microphysical properties, achieved through direct measurements in the ChArMEx experiment. On the one hand, the fact that the model can ingest such a variable input proves its feasibility. On the other hand, this work goes through a direct validation of different refractive index sets for desert dust in the thermal infrared, and pursues an assessment of the sensitivity of IASI data with respect to the dimensional distribution of desert dust particles. Results show a good consistency between calculations and observations, especially in the spectral interval $800-1000 \mathrm{~cm}^{-1}$; further, the comparison between calculations and observations suggests that further efforts are needed to better characterize desert dust optical properties in the shortwave (above $2000 \mathrm{~cm}^{-1}$ ). Whatever the case, we show that it is necessary to properly tune the refractive indices according to the geographical origin of the observed aerosol.
\end{abstract}

\section{Introduction}

The discussion about the possibility to detect and characterize atmospheric aerosols in the thermal infrared spectral range is relatively recent (Hollweg et al., 2006; Clarisse et al., 2013; Cuesta et al., 2015; Sellitto and Legras, 2016) and very active, since infrared satellite observations enable an extensive spatial-temporal characterization of aerosol optical and microphysical properties, and quantitative description of their transport processes (e.g. Peyridieu et al., 2013; Sellitto et al., 2016; Prata and Prata, 2012). However, proficient exploitation of satellite infrared data requires a good knowledge of the spectral properties of the most common atmospheric aerosols in this spectral range.

In this context, there can be several sources of uncertainty, such as poor characterization of complex refractive indices, the particle size distribution, the aerosol's vertical profile on the spatial scale of interest (Vandenbussche et al., 2013), and the degree of robustness of radiative transfer, which should be able to consistently reproduce the radiative impact of aerosols.

All these issues have been already investigated, leading to a significant improvement of the physics of radiative transfer and retrievals in the presence of aerosols (e.g. Banks et al., 2013), as far as both accuracy and computational performances are concerned. The two aspects have the same importance, since both the quality and the amount of infrared data produced by satellite-based sensors have steeply increased in the last decade. In this respect, before going through the exploration of aerosol properties, we describe the radiative transfer model we use in this work, called $\sigma$-IASI-as, fo- 
cusing on the scheme implemented to simulate the radiative effect of clouds and aerosols, and on its computational performance. The model, which is conceived mainly for research purposes, has been already successfully used in the simultaneous retrieval of several polluting gaseous species together with the thermodynamic state of surface and atmosphere (Liuzzi et al., 2016) with the Infrared Atmospheric Sounder Interferometer (IASI; Hilton et al., 2012). In this work, instead, we perform a simulation exercise in which we use the model to reproduce the observed radiance in the presence of aerosols and clouds. The ability of the model to deal with a range of atmospheric aerosols, with arbitrary vertical profiles and dimensional distributions, is one of the main advances with respect to the former $\sigma$-IASI model (Amato et al., 2002), which was conceived to work only with simplified single-layer cloud models, in which the cloud was characterized by its own temperature and emissivity. The new version of the model, instead, works with the spectrally variable complex refractive index of aerosols and clouds (water/ice), performing ab initio Mie calculations, and adopting robust and well-validated schemes for the fast parameterization of multiple scattering effects.

In this respect, it is fair to point out that $\sigma$-IASI-as computes the extinction due to aerosol/cloud particles adopting a strategy which is similar to that of other fast radiative transfer models, such as the Radiative Transfer for TOVs model (RTTOV; Saunders et al., 2013), massively employed in data assimilation in the context of numerical weather prediction (NWP). The approach we will describe is significantly faster than the exact multiple scattering effects calculation implemented in line-by-line models such as LBLRTM (Clough et al., 2005), and the Discrete Ordinates Radiative Transfer Program for a Multi-Layered Plane-Parallel Medium (DisORT; Stamnes et al., 1988). The scheme used in $\sigma$-IASI-as is a compromise between a fully parameterized one and an exact multiple scattering algorithm. Furthermore, like its predecessor $\sigma$-IASI, $\sigma$-IASI-as is not customized for any particular instrument, and works in a pseudo-monochromatic fashion: in this way the model is of more general application than the majority of predictor-based radiative transfer models. Also, since the model ingests the optical properties of several aerosol and cloud types, it can be applied to simulate infrared observations including all the variability of such properties.

The present study completes the picture of the model capabilities, which have been already investigated in depth in Liuzzi et al. $(2014,2016)$ as far as gases are concerned. As stated before, an incomplete or inaccurate characterization of the atmospheric aerosol could be the greatest source of uncertainty in radiative transfer calculations. Thus, for this validation exercise, we have fruitfully employed the aerosol microphysical properties (i.e. dimensional distribution and concentration) derived during the Chemistry-Aerosol Mediterranean Experiment (ChArMEx; Mallet et al., 2016), special observation period (SOP) 1a. One of the components of SOP1 was the ADRIMED field campaign (Aerosol Direct Radiative Impact on the regional climate in the MEDiterranean region). Here, we exploit the measurements acquired on board the ATR-42 aircraft, operated by SAFIRE (Service des Avions Francais Instruments pour la Recherche en Environnement, http://www.safire.fr/) over Lampedusa, on four different days between June and July 2013. Indeed, natural aerosols largely affect the radiative transfer in the Mediterranean Basin atmosphere in a direct or indirect way (e.g. Di Sarra et al., 2008, 2011; Pace et al., 2005, 2006; Di Biagio et al., 2010; Meloni et al., 2015). At the location and the time of the observations we have chosen, the dominant contribution has been found to be that of the desert dust emissions from various Northwest African soils. For our purposes, we have used the dimensional properties and profiles derived from ATR42 flights (details in Denjean et al., 2016), and produced radiative transfer calculations with different sets of complex refractive indices, according to the soil from which aerosol has been observed to come: such an exercise is devoted to quantify the accuracy of our knowledge of desert dust optical properties in the thermal infrared. This will be made on the full IASI spectral coverage (3.62 to $15.5 \mu \mathrm{m}$ ) in order to see whether or not input refractive indices fail to represent the observed radiance in spectral regions dominated either from aerosol absorption or scattering.

The paper is organized as follows: in Sect. 2 we will describe the $\sigma$-IASI-as model, with the aerosol extinction calculation scheme implemented therein; Sect. 3 is dedicated to show the IASI data and related ancillary information used in this case study. In Sect. 4 we will conduct an in-depth analysis of results, with a particular focus on refractive indices consistency. Conclusions are drawn in the final section.

\section{The $\sigma$-IASI-as radiative transfer model}

The radiative transfer model we work with is called $\sigma$-IASIas. As already stated, it is an advanced version of the $\sigma$ IASI model (Amato et al., 2002) as far as cloud and aerosol treatment is concerned. The model is tailored to compute the Earth/atmosphere-emitted radiance in the wave number interval $100-3000 \mathrm{~cm}^{-1}$, and works within the assumption of a plane-parallel geometry. Moreover, although most of the forthcoming discussion is based on the hypothesis of an observer located at the top of the atmosphere, the model is capable of computing both ground-based and satellite-based radiance.

The radiative transfer equation solved in $\sigma$-IASI-as takes the following form, in which the total observed radiance $R(\sigma)$ at wave number $\sigma$ is expressed as the sum of four terms: 


$$
\begin{aligned}
& R(\sigma)=R^{\text {surf }}(\sigma)+R^{\uparrow}(\sigma)+R^{\downarrow}(\sigma)+R^{\text {sun }}(\sigma) \\
& =\epsilon_{g} B\left(T_{g}\right) \tau_{0}+\int_{0}^{+\infty} B(T) \frac{\partial \tau}{\partial z} \mathrm{~d} z \\
& \quad+\left(\epsilon_{g}-1\right) \tau_{0} \int_{0}^{+\infty} B(T) \frac{\partial \tau_{*}^{f}}{\partial z} \mathrm{~d} z+\frac{1-\epsilon_{g}}{\pi} \tau^{\prime} \mu_{\mathrm{s}} I_{\mathrm{s}},
\end{aligned}
$$

where the first term represents the radiance emitted directly by the surface, with a skin temperature $T_{g}$, an emissivity $\epsilon_{g}(\sigma)$, and attenuated by the atmosphere along the observation path, whose total transmittance is $\tau_{0}(\sigma)$. The second term is the up-welling radiance, namely the radiance emitted directly from the atmosphere along the slant path in the viewing direction, integrated along the path itself. The third term expresses the down-welling radiance, which is the radiance contribution emitted from the atmosphere towards surface, back-reflected from it and that reaches the observer; according to the type of surface, the term $\tau_{*}^{f}$ is computed in different ways; if the surface is a Lambertian diffuser, $\tau_{*}^{f}$ is the diffuse transmittance, that can be calculated as the transmittance function at a suitable angle, corresponding to an effective zenith angle $\theta_{r}=52.96$ degrees (Elsasser, 1942). In the case of a specular reflector (e.g. sea surface), instead, $\tau_{*}^{f}$ will be the nadir transmittance, exponentially rescaled by the cosine of the viewing zenith angle (VZA). Finally, the last term represents the solar radiance $I_{\mathrm{S}} / \pi$ reflected back from surface and then reaching the observer, with $\tau^{\prime}$ the two-way transmittance along the Sun-surface-observer path, and $\mu_{\mathrm{s}}$ the cosine of the solar zenith angle. The solar irradiance $I_{\mathrm{S}}$ implemented in the model is borrowed by the Kurucz model (Chance and Kurucz, 2010). Formally speaking, $\tau^{\prime}$ is the only term that undergoes a modification, according to the geometry (nadir-looking or zenith-looking): in this second case, the two-way transmittance simplifies to one-way, along the observation path. The other terms remain unaltered.

In a non-scattering atmosphere, Eq. (1) can be used to estimate the observed radiance both in clear sky and in the presence of aerosol/cloud particles. Under the further limitation that the instrumental field of view (FOV) is not affected by cloud shadows or other weird inhomogeneities, the total observed radiance will be the sum of two terms, one of clear sky and the other that is related to the overcast fraction $\alpha$ of the FOV (Chanine, 1974):

$$
R(\sigma)=(1-\alpha) R_{\mathrm{C}}(\sigma)+\alpha R_{\mathrm{cld}}(\sigma) .
$$

The term $R_{\mathrm{C}}(\sigma)$ in Eq. (2) is expressed by Eq. (1), and is the clear-sky radiance. The cloudy radiance $R_{\text {cld }}(\sigma)$, at first order, is formally calculated in the same way; the transmittance is calculated taking into account not only gas optical depth, but also cloud opacity. At second order, an additional term ought to be considered to account for possible sunglint

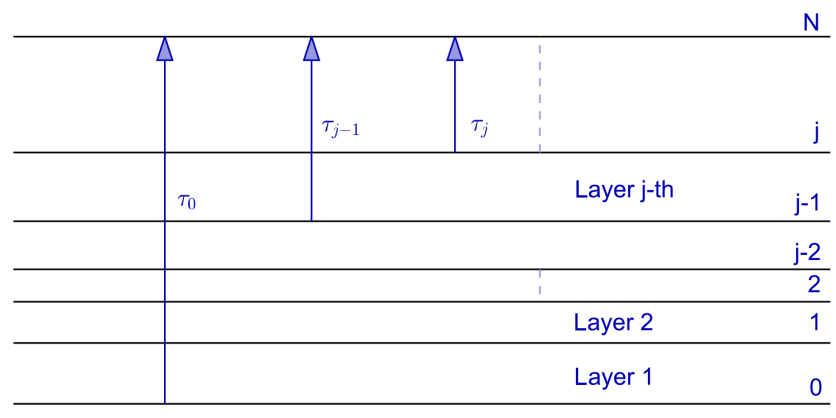

Figure 1. Layering scheme of the atmosphere, with layer numbering and the definition of transmittances.

effects caused by reflection of solar radiation by cloud top or sea surface. Such a contribution becomes important only at wave numbers greater than $2000 \mathrm{~cm}^{-1}$, while it is negligible in the thermal infrared. However, since in the analysis we conduct we preliminarily discard spectra affected by such effects, the calculation of this term is not implemented in $\sigma$ IASI-as.

The radiative transfer Eq. (1) is solved in the model in its discrete form. The atmosphere is divided into a number of discrete layers, each one assumed to be characterized by a homogeneous temperature and composition. Hence, one can write two expressions for $R_{\mathrm{C}}$ and $R_{\mathrm{cld}}$ :

$$
\begin{aligned}
& R_{\mathrm{C}}=\epsilon_{g} B\left(T_{g}\right) \tau_{0, \mathrm{C}}+\sum_{j=1}^{N_{L}} B\left(T_{j}\right)\left(\tau_{\mathrm{C}, j}-\tau_{\mathrm{C}, j-1}\right) \\
& +\left(\epsilon_{g}-1\right) \tau_{0, \mathrm{C}} \sum_{j=1}^{N_{L}} B\left(T_{j}\right)\left(\tau_{\mathrm{C}, j *}^{f}-\tau_{\mathrm{C}, j-1 *}^{f}\right)+\frac{1-\epsilon_{g}}{\pi} \tau_{\mathrm{C}}^{\prime} \mu_{\mathrm{s}} I_{\mathrm{s}}, \\
& R_{\mathrm{cld}}=\epsilon_{g} B\left(T_{g}\right) \tau_{0, \mathrm{cld}}+\sum_{j=1}^{N_{L}} B\left(T_{j}\right)\left(\tau_{\mathrm{cld}, j}-\tau_{\mathrm{cld}, j-1}\right) \\
& +\left(\epsilon_{g}-1\right) \tau_{0, N} \sum_{j=1}^{N_{L}} B\left(T_{j}\right)\left(\tau_{\mathrm{cld}, j *}^{f}-\tau_{\mathrm{cld}, j-1 *}^{f}\right)+\frac{1-\epsilon_{g}}{\pi} \tau_{\mathrm{cld}}^{\prime} \mu_{\mathrm{s}} I_{\mathrm{s}} .
\end{aligned}
$$

The dependence on the wave number $\sigma$ is omitted for brevity. In both equations, $\tau_{j}$ is the total transmittance from the top of the $j$ th layer to $\infty$, and $\tau_{j-1}$ is the total transmittance from the bottom of the $j$ th layer to $\infty$, leading $\tau_{\mathrm{cld}, L}=1$. For clarification see Fig. 1. In addition, $T_{j}$ is the equivalent average temperature of the bulk of the $j$ th layer. In $\sigma$-IASI-as, the atmospheric grid is made up of 60 layers, whose pressure boundaries are fixed, and span the interval 1013-0.005 mbar: hence, the number of layers for which transmittance is computed depends strictly on surface pressure, taking into account the air mass above the observed target. In Amato et al. (2002), it is demonstrated that $N_{L}=60$ is enough to confine the radiative transfer error well below $0.1 \mathrm{~K}$ throughout the whole IASI spectral range. 
Transmittances in the clear-sky and cloudy radiances are defined according to the considered absorbers. In $\sigma$-IASI-as it is assumed that the clear-sky transmittance is affected both by gases and aerosol particles, namely assuming that aerosols are uniformly distributed on the entire FOV. The extinction due to water and ice clouds, together with that due to gases and other aerosols, yield the transmittance in the cloudy portion $\alpha$ of the FOV. Looking at Fig. 1, it is possible to write explicitly the expressions for the transmittance $\tau_{j}$ in the cases of clear and cloudy sky:

$\tau_{\mathrm{C}, j}=\prod_{i=1}^{j} \exp \left(-\chi_{\mathrm{C}, i}\right)=\prod_{i=1}^{j} \exp \left[-\left(\chi_{\mathrm{gas}, i}+\chi_{\mathrm{aer}, i}\right)\right]$

$\tau_{\mathrm{cld}, j}=\tau_{\mathrm{C}, j} \cdot \prod_{i=1}^{j} \exp \left(-\chi_{\mathrm{cld}, i}\right)$,

where $\chi_{\mathrm{C}, i}$ is single-layer total optical depth in the absence of clouds, and $\chi_{\mathrm{aer}, i}$ and $\chi_{\mathrm{cld}, i}$ are the optical depth of aerosol and clouds in the $i$ th layer.

Calling $\eta_{j}$ the single-layer transmittance of the $j$ th layer, and using the definitions provided so far, we can better express the relation between $\eta_{j}$ and the sum of the optical depths of all the atmospheric absorbers in the layer itself as

$\eta_{j}(\sigma)=\frac{\tau_{j-1}(\sigma)}{\tau_{j}(\sigma)}=\exp \left[-\sum_{i=1}^{S} \chi_{i, j}(\sigma)\right]$

with $S$ being the number of atmospheric absorbers, and $\chi_{i, j}(\sigma)$ the monochromatic optical depth of the $i$ th species from the top of the $j$ th layer to its bottom at wave number $\sigma$. The simplest way to express $\chi_{i, j}(\sigma)$ is to recall the wellknown Lambert-Beer law

$\chi_{i, j}(\sigma)=q_{i, j} k_{i, j}(\sigma) \Delta h_{j}$,

where $q_{i, j}$ is the concentration of the $i$ th species in the $j$ th layer, $k_{i, j}(\sigma)$ is the absorption coefficient for that species at wave number $\sigma$, and $\Delta h_{j}=H_{j} / \cos \theta$ denotes the path length, along the $\theta$-direction of observation, from the bottom of the $j$ th layer to its top, $H_{j}$ being the thickness of the $j$ th layer.

The way in which the term $k_{i, j}(\sigma)$ is treated in the model depends strictly on the type of absorber: since a different physics regulates the interaction of radiation with gases and particles, the estimation of $k_{i, j}(\sigma)$ relies on two distinct approaches, one for gases and one for aerosols and clouds, which are described in what follows.

\subsection{Gas optical depths}

The $\sigma$-IASI-as code calculation of gas optical depths is based on a scheme which avoids the direct manipulation of spectroscopy. In contrast, the approach followed is that of working in a pseudo-monochromatic context, in which transmittances are calculated on an equally spaced wave number grid.
To do this, the $\sigma$-IASI-as architecture embodies a wide lookup table where - for each layer, atmospheric species, and wave numbers - optical depths are pre-computed and stored. Then, optical depths are rescaled with air pressure and temperature: on the one hand, pressure is fixed by the different atmospheric layers; on the other hand, the dependence on temperature is parameterized: purely monochromatic optical depths are generated using the version 12.2 of LBLRTM (Clough et al., 2005), equipped with the spectral library AER v_3.2 with the continuum model MT-CKD v_2.5.2 (Mlawer et al., 2012) using as input parameters the reference temperature profile US Standard Atmosphere 1962 (Anderson et al., 1986), with the associated reference gases concentrations. Without varying them, optical depths are re-calculated using the same temperature profile translated by eight evenly spaced temperature values ranging from -40 to $+40 \mathrm{~K}$. This choice is adequate to take into account the usual temperature variations that occur in the Earth's atmosphere.

Once optical depths have been calculated, for each individual species (except for water vapour), layer, and wave number, the behaviour of the optical depth with temperature is parameterized by a second-order polynomial:

$\chi_{i, j}^{\sigma}=q_{i, j}\left(c_{0, i, j}^{\sigma}+c_{1, i, j}^{\sigma} \Delta T_{j}+c_{2, i, j}^{\sigma}\left(\Delta T_{j}\right)^{2}\right)$,

where $\Delta T_{j}$ is the difference between the reference temperature profile and the actual equivalent temperature of the $j$ th layer, and $q_{i, j}$ is the concentration of the $i$ th gas in the $j$ th layer. Water vapour optical depth, instead, is modelled using a slightly different parameterization: in order to take into account the effects depending on gas concentration, such as self-broadening of spectral lines, the polynomial expression includes a further coefficient $c_{3,1, j}^{\sigma}$ (Masiello and Serio, 2003), which multiplies the water vapour concentration:

$\chi_{1, j}^{\sigma}=q_{1, j}\left(c_{0,1, j}^{\sigma}+c_{1,1, j}^{\sigma} \Delta T_{j}+c_{2,1, j}^{\sigma}\left(\Delta T_{j}\right)^{2}+c_{3,1, j}^{\sigma} q_{1, j}\right)$,

where the water vapour species is denoted by $i=1$, holding the species ordering of the HITRAN database (Rothman et al., 2013). In order to reduce the dimensionality of calculations with respect to line-by-line models, the coefficients of the polynomial parameterizations are binned on a pseudomonochromatic spectral grid with $\Delta \sigma=10^{-2} \mathrm{~cm}^{-1}$.

The present version of $\sigma$-IASI-as can compute the observed radiance with a user-specified temperature and emissivity, atmospheric profiles of temperature, and specific profiles for $\mathrm{H}_{2} \mathrm{O}, \mathrm{HDO}, \mathrm{O}_{3}, \mathrm{CO}_{2}, \mathrm{CO}, \mathrm{CH}_{4}, \mathrm{~N}_{2} \mathrm{O}, \mathrm{HNO}_{3}, \mathrm{SO}_{2}$, $\mathrm{NH}_{3}$, OCS, and $\mathrm{CF}_{4}$. Besides these gases, the code computes the optical depth of an ensemble of other gases whose concentration is kept fixed (mixed gases). This set includes the major species $\mathrm{N}_{2}$ and $\mathrm{O}_{2}$, which are considered through their continuum. Moreover, the model considers other trace gases, such as $\mathrm{NO}, \mathrm{NO}_{2}, \mathrm{HCl}, \mathrm{HCN}, \mathrm{CH}_{3} \mathrm{Cl}, \mathrm{OH}, \mathrm{H}_{2} \mathrm{CO}$, and $\mathrm{C}_{2} \mathrm{H}_{2}$. Their reference vertical profiles are fixed according to the US Standard atmosphere (Anderson et al., 1986). 
Mixed gases include also the heavy CFC molecules $\mathrm{CCl}_{4}$, CFC-11, CFC-12, and HCFC-22. Their column abundance is scaled consistently with the most recent World Data Centre for Greenhouse Gases report (WDCGG, 2015). It is fair to point out that, among the available fast radiative transfer models, $\sigma$-IASI-as is the more flexible in terms of number of gaseous species whose concentration can be tuned. Furthermore, the analytical parameterization expressed by Eqs. (9)(10) enables the possibility to compute, within the model, the derivatives of the radiance (namely, Jacobians) with respect to all the atmospheric and surface parameters mentioned above (for details see Amato et al., 2002).

\subsection{Aerosol and cloud optical depths}

The $\sigma$-IASI-as model works with a physically based method also to compute the extinction due to aerosol particles and clouds. To treat them, the model exploits an ab initio approach: the code embodies Mie routines (Bohren and Huffmann, 2000; Massie and Hervig, 2013) which are called iteratively within the calculation of single-layer transmittances. The results of Mie calculations are manipulated according to the scheme described in Chou et al. (1999) for calculating effective aerosol and cloud optical depths. According to this, the aerosol optical depth at a given wave number $\sigma$ and a given layer $j$ is computed as follows:

$\chi_{\mathrm{aer}, j}(\sigma)=q_{\mathrm{aer}, j} k_{\mathrm{aer}, j}(\sigma) \Delta h_{j}$,

where $q_{\text {aer, } j}$ is the aerosol concentration [particles $\mathrm{cm}^{-3}$ ], and $\Delta h_{j}$ has the same meaning as in Eq. (8), while $k_{\text {aer, } j}(\sigma)$ is the equivalent aerosol extinction per particle $\left[\mathrm{km}^{-1}\right]$.

In the scheme of (Chou et al., 1999), $k_{\mathrm{aer}, j}(\sigma)$ includes the effects of three processes: emission, absorption, and scattering. These three processes are in fact quite coupled, and there is no way to exactly take them into account at the same time. Despite this, there are several possible approximations that can be used to do this: the scheme implemented in $\sigma$-IASI-as estimates multiple scattering effects in the longwave, yielding an equivalent aerosol optical depth. In this sense, this is comparable to an "absorption approach".

Hence, at a given wave number $\sigma$ and for the layer $j$ th (subsequently omitted for conciseness), the term $k_{\mathrm{aer}, j}(\sigma)$ can be expressed as

$k_{\mathrm{aer}}(\sigma)=\beta_{\mathrm{ext}}(\sigma)[(1-\omega(\sigma))+b(\sigma) \omega(\sigma)]$,

where $\beta_{\text {ext }}(\sigma)$ is the extinction efficiency per particle $\left[\mathrm{km}^{-1}\right]$, $\omega(\sigma)$ is the single-scattering albedo, and $b(\sigma)$ is the mean fraction of radiation scattered in the upward direction. In the hypothesis that the incoming radiation is isotropic, $b(\sigma)$ is the integral average in the upward direction (first integral) of the cumulative function (second integral) of the scattering phase function $b(\sigma)=\frac{1}{2} \int_{0}^{1} \mathrm{~d} \mu \int_{-1}^{0} \mathrm{~d} \mu^{\prime} P\left(\mu, \mu^{\prime}, \sigma\right)$,

where $\mu=\cos (\theta)$ and $P\left(\mu, \mu^{\prime}, \sigma\right)$ is the scattering phase function. In this way, the code bypasses the exact calculation of multiple scattering effects, by parameterizing them in a semi-analytical way. The Henyey-Greenstein phase function (Henyey and Greenstein, 1941) is implemented, since it is the most common one for atmospheric applications. It is not directly computed in its original integral form, in order not to introduce an unsustainable computational load. Instead, $b(\sigma)$ is expressed as a third-order polynomial of the asymmetry parameter $g(\sigma)$ :

$b(\sigma)=1-\sum_{l=1}^{4} a_{l} g^{l-1}(\sigma)$,

where the four coefficients of the linear combination are fixed: $a_{1}=0.5, a_{2}=0.3738, a_{3}=0.0076$, and $a_{4}=0.1186$.

All the quantities involved in the aerosol/cloud extinction calculations depend on the microphysical properties of particles, namely their dimensional distribution and their complex refractive indices. The $\sigma$-IASI-as can compute aerosol and cloud extinction due to an arbitrary number of aerosols and a superposition of a user-defined number of log-normal modes, which are computed within the code on the basis of user-defined average radius, standard deviation, cut-offs, and concentration on 100 points. Calculations are performed on a wave number grid with $\Delta \sigma=15 \mathrm{~cm}^{-1}$, which is fine enough to correctly reproduce the absorption features of all the atmospheric aerosols. Results are subsequently interpolated on the wave number grid used to compute gas optical depths.

The $\sigma$-IASI-as code has a built-in routine that includes the complex refractive indices of the most common atmospheric aerosols, borrowed from existing databases (Shettle and Fenn, 1979; Hess et al., 1998; Massie and Hervig, 2013), and of water ice (Warren, 1984), and water vapour for cloud extinction calculations. The aerosols handled by the code are listed in Table 1. For these aerosols, the code can compute also radiance Jacobians with respect to their concentration.

\subsection{Code performance and potentialities}

The computational performance of the code varies according to the complexity of cloud and aerosol vertical profiles, the number of log-normal modes involved, and due to the fact that Jacobians are computed or not. A clear-sky single IASI spectrum (8461 channels) needs $1.0 \mathrm{~s}$ to be computed on a modern CPU. This time increases by $\sim 0.1 \mathrm{~s}$ for each $\log$ normal aerosol/cloud mode; this is comparable to other fast models such as RTTOV (Faijan et al., 2012). The calculation of a full IASI spectrum with all the Jacobians (with respect to surface temperature, emissivity, temperature profile, gas and 
Table 1. List of the aerosols included in the $\sigma$-IASI-as model.

\begin{tabular}{|c|c|}
\hline \multicolumn{2}{|c|}{ Aerosol types } \\
\hline Water droplets & Ice crystals \\
\hline $\mathrm{NaCl}$ & Sea salt ${ }^{\mathrm{a}}$ \\
\hline Hydrophilic aerosol & $\mathrm{NH}_{3}$ droplets \\
\hline Carbonaceous aerosol & Volcanic dust \\
\hline $\mathrm{H}_{2} \mathrm{SO}_{4}$ droplets ${ }^{\mathrm{b}}$ & Meteoric dust \\
\hline Quartz $^{\mathrm{c}}$ & Hematite $^{c}$ \\
\hline Desert sand ${ }^{\mathrm{c}}$ & Saharan dust \\
\hline Volcanic ash & Flame soot \\
\hline Ammonium sulphate & Burning vegetation ash \\
\hline
\end{tabular}

${ }^{a}$ Sea salt refractive indices are available for eight different values of relative humidity (0 to $99 \%$ ).

${ }^{b} \mathrm{H}_{2} \mathrm{SO}_{4}$ droplets are available for two temperature values: 215 and $300 \mathrm{~K}$.

${ }^{c}$ Birefringent materials: each of them has two sets of refractive indices - one for the ordinary light ray and the other for the extraordinary one. This is convenient if $\sigma$-IASI-as is used to simulate polarized radiances.

aerosol/cloud concentrations) requires some $\sim 6.0 \mathrm{~s}$, which means $0.04 \mathrm{~s}$ per 50 spectral channels. The time includes that required to read the optical depths look-up table.

As already stated, the way in which the code computes the observed radiance is not dependent on the instrumental technical characteristics, because of the pseudo-monochromatic approach, differently from other, common parametric methods based on predictors. This feature makes the code adaptable to any kind of instrument which observes in the infrared, simply by changing the spectral response function in the code, and not its architecture, which is a unique in the context of fast radiative transfer models.

Another relevant features of $\sigma$-IASI-as is its capability to deal with different surface types, hence different reflection geometries from surface, both Lambertian (e.g. on most land surfaces) and specular (e.g. on the sea surface), without any degradation in code performance.

The radiative transfer scheme at the basis of $\sigma$-IASI-as has been subjected to several validation steps and applied in many contexts (e.g. Liuzzi et al., 2016; Masiello et al., 2009; Masiello and Serio, 2013) and is based on robustly assessed procedures as far as aerosol and cloud extinction estimation is concerned (Chou et al., 1999).

\section{Data and methods}

\subsection{IASI data}

The analysis that follows consists of a direct comparison between the radiance simulated using $\sigma$-IASI-as, which requires atmospheric profiles of temperature, gases, and aerosols, together with their spectral refractive indices, and their dimensional characterization, and the collocated observations in the thermal infrared from the IASI interferometer. As already stated, besides the explanation of $\sigma$-IASI-as ar- chitecture, the goal of this study is to quantify the sensitivity of IASI data with respect to the geographical origin of desert dust aerosol. Its optical properties have been already explored in many studies, such as Berthier et al. (2006); Smith and Grainger (2014); Chen et al. (2011).

Klüser et al. $(2012,2015)$ have estimated the information content of IASI spectra with respect to desert dust aerosol properties and mineralogical composition. Here we further investigate this topic, assessing new, independently measured optical parameters of desert dust.

IASI (Hilton et al., 2012) was developed in France by CNES and is flying on board the MetOp platforms. The two MetOp satellites (A and B) are part of the EUMETSAT European Polar System (EPS). IASI was conceived for meteorological studies; hence, its main aim is to provide suitable information on the thermodynamic status of atmosphere (temperature and water vapour profiles) and surface. The instrument works in the whole spectral interval from 645 to $2760 \mathrm{~cm}^{-1}$, with a sampling interval $\Delta \sigma$ equal to $0.25 \mathrm{~cm}^{-1}$ and an effective apodized resolution of $0.5 \mathrm{~cm}^{-1}$, which results in 8461 spectral channels for each single spectrum. Since MetOp platforms are on a polar orbit, IASI works as a cross-track scanner, with 30 effective fields of regard (FOR) per scan, spanning an angle range of \pm 48.33 degrees on both sides of the nadir. Each FOR consists of a $2 \times 2$ matrix of socalled instantaneous fields of view (IFOVs); each IFOV has a diameter of $14.65 \mathrm{mrad}$, corresponding to a ground resolution of $12 \mathrm{~km}$ at nadir at a satellite altitude of $819 \mathrm{~km}$. The IFOV matrix is centred on the viewing direction. Hence, at nadir, the FOR of the four IASI pixels projects at the ground a square area of $\sim 50 \times 50 \mathrm{~km}$. A more exhaustive description of IASI, the mission objectives and its achievements can be found in Hilton et al. (2012). IASI data were downloaded from the EUMETSAT data centre.

For the present study, we delimited a geographic box around the island of Lampedusa, defined by the latitude range $\left[35.0^{\circ} \mathrm{N}, 36.0^{\circ} \mathrm{N}\right]$ and longitude $\left[12.0^{\circ} \mathrm{E}, 13.2^{\circ} \mathrm{E}\right]$. Morning IASI soundings were collected in this area on 22 and 28 June, and 3 July 2013. These three days are characterized by different atmospheric desert dust loads and vertical profile shapes: this is the ideal case to characterize the effectiveness of aerosol parameters in different conditions. The geographic area of interest, together with the exact location of IASI soundings, are reported in Fig. 2. Only clear-sky IFOVs are indicated; they are pre-selected through a scene analysis software based on a cumulative discriminant analysis approach (Amato et al., 2014). A further selection is made discarding all the spectra affected by sunglint contamination, which are not useful to characterize the accuracy of aerosol spectral properties at wave lengths shorter than $5 \mu \mathrm{m}$. This pre-filtering process yielded a total of 12 IASI IFOVs (out of 22 clear sky) actually used in this work, for the case of 22 June; 15 IFOVs (out of 23) for the 28 June case; and, finally, 18 IFOVs for the case of 3 July. The acquisition times are, respectively, 08:45, 08:21, and 08:17 UTC. 

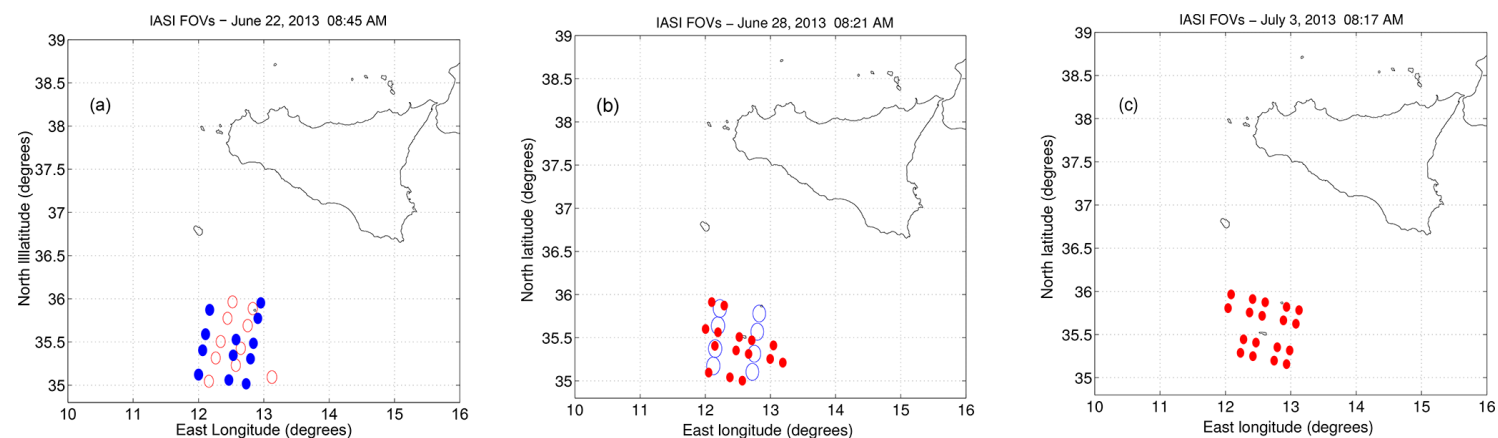

Figure 2. Location of the IASI fields of view analysed in this work. From left to right: 22 June, 28 June, and 3 July 2013 . Red circles correspond to those acquired from IASI on board of MetOp-A, blue from IASI on board of MetOp-B. Filled footprints are those that have been effectively used, while those unfilled have not been exploited because of strong sunglint contamination in the shortwave.

Table 2. From top to bottom: log-normal modes used to fit the observed size distributions on 22 June (top), 28 June (middle) and 3 July (bottom) for each altitude range.

\begin{tabular}{|c|c|c|c|c|c|c|}
\hline & & Mode 1 & Mode 2 & Mode 3 & Mode 4 & Origin \\
\hline \multirow{3}{*}{$140-1400 \mathrm{~m}$} & $N_{\text {tot }}$ & 500.00 & 900.00 & 5.00 & 0.40 & \multirow{3}{*}{ Southern Morocco } \\
\hline & $R_{0}(\mu \mathrm{m})$ & 0.045 & 0.070 & 0.140 & 0.675 & \\
\hline & $\sigma_{0}$ & 1.50 & 1.50 & 1.55 & 2.80 & \\
\hline \multirow{3}{*}{$1400-3600 \mathrm{~m}$} & $N_{\text {tot }}$ & 500.00 & 900.00 & 8.00 & 1.20 & \multirow{3}{*}{ Southern Morocco } \\
\hline & $\mathrm{R}_{0}(\mu \mathrm{m})$ & 0.039 & 0.070 & 0.185 & 0.650 & \\
\hline & $\sigma_{0}$ & 1.28 & 1.50 & 1.55 & 2.18 & \\
\hline \multirow{4}{*}{$3600-5800 \mathrm{~m}$} & $N_{\text {tot }}$ & 130.00 & 100.00 & 20.00 & 3.20 & \multirow{3}{*}{ Southern Algeria } \\
\hline & $R_{0}(\mu \mathrm{m})$ & 0.039 & 0.070 & 0.200 & 0.775 & \\
\hline & $\sigma_{0}$ & 1.28 & 1.50 & 1.55 & 2.18 & \\
\hline & & Mode 1 & Mode 2 & Mode 3 & Mode 4 & Mode 5 \\
\hline \multirow{3}{*}{$150-1000 \mathrm{~m}$} & $N_{\text {tot }}$ & 800.00 & 200.00 & 10.00 & 0.35 & 0.01 \\
\hline & $R_{0}(\mu \mathrm{m})$ & 0.045 & 0.065 & 0.150 & 0.250 & Tunisia \\
\hline & $\sigma_{0}$ & 1.30 & 1.50 & 1.35 & 2.40 & 2.00 \\
\hline \multirow{4}{*}{$1000-5400 \mathrm{~m}$} & $N_{\text {tot }}$ & 500.00 & 400.00 & 20.00 & 1.70 & \multirow{3}{*}{ Tunisia } \\
\hline & $R_{0}(\mu \mathrm{m})$ & 0.039 & 0.070 & 0.175 & 0.500 & \\
\hline & $\sigma_{0}$ & 1.25 & 1.50 & 1.55 & 2.70 & \\
\hline & & Mode 1 & Mode 2 & Mode 3 & Mode 4 & Origin \\
\hline \multirow{3}{*}{$1600-3500 \mathrm{~m}$} & $N_{\text {tot }}$ & 300.00 & 500.00 & 20.00 & 2.50 & \multirow{3}{*}{ Southern Morocco } \\
\hline & $R_{0}(\mu \mathrm{m})$ & 0.035 & 0.055 & 0.165 & 0.450 & \\
\hline & $\sigma_{0}$ & 1.25 & 1.50 & 1.55 & 2.50 & \\
\hline \multirow{3}{*}{$3500-4800 \mathrm{~m}$} & $N_{\text {tot }}$ & 100.00 & 160.00 & 15.00 & 2.00 & \multirow{3}{*}{ Tunisia } \\
\hline & $R_{0}(\mu \mathrm{m})$ & 0.040 & 0.060 & 0.185 & 0.800 & \\
\hline & $\sigma_{0}$ & 1.25 & 1.50 & 1.55 & 1.80 & \\
\hline
\end{tabular}

\subsection{Radiative transfer input data and methods}

In relation to simulations, the radiative transfer model relies on proper input data for surface properties, atmospheric state, and aerosol vertical distributions. As far as emissivity is concerned, since all the IASI IFOVs that we examine involve sea surface, emissivity is computed according to Masuda's emissivity model (Masuda et al., 1988). We have developed a look-up table with sea surface emissivity over the IASI spectral range and resolution. The emissivity has been precomputed for VZA values spanning the interval from 0 to $50^{\circ}$ (in steps of $1^{\circ}$ ) and for an average wind speed of $5 \mathrm{~m} \mathrm{~s}^{-1}$.

For surface temperature and atmospheric status, we used the analyses provided by the European Centre for Medium- 

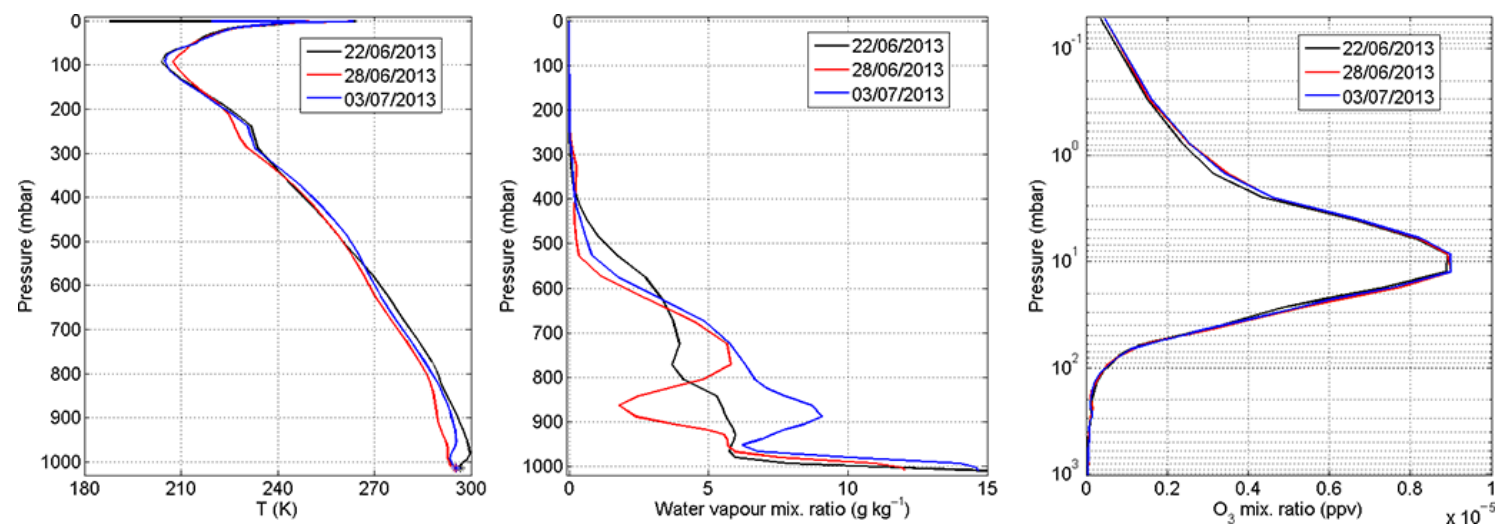

Figure 3. From left to right: ECMWF spatial-temporal average profiles for temperature (left), water vapour (middle), and ozone (right) on the days involved in this analysis. Together with the temperature profiles, ECMWF average surface temperatures for each day are also indicated by markers.

Range Weather Forecasts (ECMWF) collocated with IASI measurements. ECMWF provides data at the four canonical hours (00:00, 06:00, 12:00, and 18:00 UTC) on a spatial grid mesh of $0.125^{\circ} \times 0.125^{\circ}$. Since we do not retrieve atmospheric and surface parameters, they are estimated as the temporal average between the two consecutive ECMWF analyses closest to IASI soundings (mostly acquired around 09:00 UTC), namely those at 06:00 and 12:00 UTC of the three days that we consider. More specifically, we use ECMWF temperature, water vapour mixing ratio, and ozone mixing ratio profiles $(T, Q, O)$, and surface temperature $T_{\mathrm{S}}$. All these profiles are originally provided for either 91 pressure levels (until 25 June 2013) or 137 pressure levels (from 26 June 2013). Since the ECMWF pressure grid is not fixed, depending on surface pressure, all the atmospheric profiles are preliminarily averaged on the 60-layer pressure grid of $\sigma$-IASI-as. The other gases required as input from the radiative transfer model are tuned according to the most recent updates of climatology (WDCGG, 2015). The final, average $(T, Q, O)$ input profiles used for the IASI IFOVs effectively exploited for the three selected dates are shown in Fig. 3.

The last input required by radiative transfer is the aerosol vertical profile and dimensional distribution. Such data were acquired from the Forward Scattering Spectrometer Probe (FSSP-300), the Ultra High Sensitivity Aerosol Spectrometer (UHSAS), the two particle counters GRIMM-1 and GRIMM-2, and the scanning mobility particle sizer (SMPS) on board the ATR-42 aircraft (Denjean et al., 2016). These instruments measure the particle concentration in different size ranges; for this radiative closure experiment, we use the particle concentration measurements. Their diameters lie in the interval $0.05-30 \mu \mathrm{m}$ at any altitude. The dimensional distributions have been fitted with a variable number (typically 4 or 5) of log-normal modes. Different sets of log-normal modes have been found to be representative of the size distributions observed at different altitudes. The observed par- ticle size distributions on the selected days are represented in Fig. 4, while the retrieved log-normal modes to reproduce them are summarized in Table 2.

This ensemble of input data has been used to perform a double run of radiative transfer simulations: the first one is done including aerosol vertical profiles, the second one without them (clear-sky simulations). The double simulation is aimed to better characterize the radiative impact of aerosol with respect to IASI real observations. Results reported in Denjean et al. (2016) show that, on the selected dates, the observed atmospheric aerosols have a variable geographic origin: that observed over Lampedusa on 22 June has two distinct origins, according to the altitude, coming from southern Morocco for altitudes below $1500 \mathrm{~m}$, and from southern Algeria for altitudes above $3500 \mathrm{~m}$. On 28 June, instead, the observed aerosol comes entirely from Tunisia, while for the case of 3 July, the lower layer (below $3000 \mathrm{~m}$ ) comes from southern Morocco, the upper from Tunisia. All this information is summarized in Table 2 , and has been properly considered in the choice of refractive indices used for radiative transfer simulations. Indeed, to probe the sensitivity of IASI data to the heterogeneous origin of dust, two sets of simulations in the presence of aerosol have been performed: the first using the indices borrowed from Shettle and Fenn (1979), and included in the OPAC database; the second using sets of refractive indices which account for the parent soils of the observed aerosol, initially derived in Di Biagio et al. (2014) and more extensively in Di Biagio et al. (2017). In the first study, extinction spectra in the $2-16 \mu \mathrm{m}$ range were measured in situ $(T=293 \mathrm{~K}, \mathrm{RH}<2 \%)$ for poly-dispersed pure dust aerosols generated from natural parent soils in Tunisia, Niger, and the Gobi desert. Such data were used in combination with particle size distributions to calculate the complex refractive index of each dust sample. All the sets of refractive indices chosen for the present work are plotted in Fig. 5. They are averaged on a $15 \mathrm{~cm}^{-1}$ spectral grid, the same used by $\sigma$-IASI-as to compute aerosol extinction. 

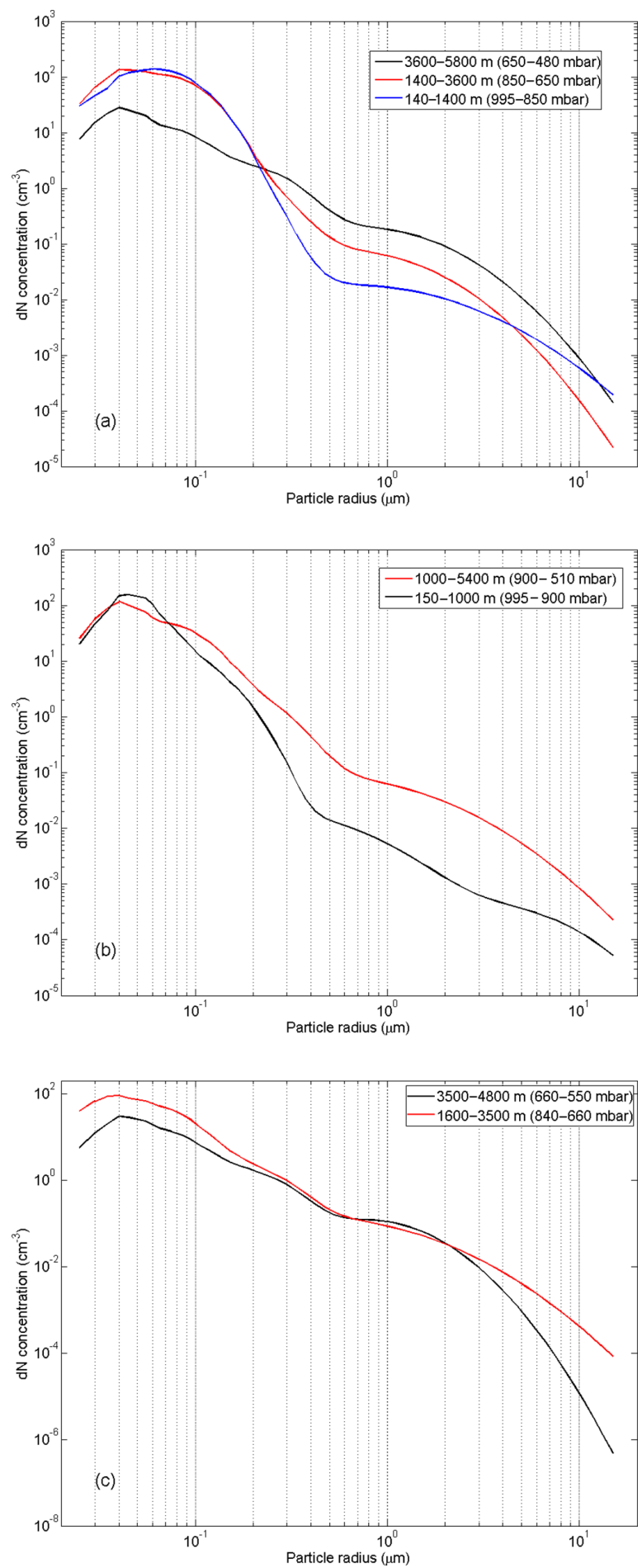

Figure 4. Measured dimensional distributions of dust aerosol by the instruments on board the ATR-42 at different altitudes: (a) 22 June, (b) 28 June, and (c) 3 July 2013. In the first case, there are three distinct dust layers, instead of two. The extra layer (blue curve) is that closest to the surface: on that day, dust aerosol is more abundant than in the other two cases.
It is fair to stress that a more complex simulation should also consider the presence of polluted aerosol particles in the boundary layer, and their mixing with dust particles. However, we have neglected such effects, since IASI radiances (as shown e.g. in Vandenbussche et al., 2013) have usually a very limited sensitivity to aerosols in the atmospheric layers where mixing takes place; also, in cases like this, where the observed target is sea surface, the thermal contrast between surface and the boundary layer is limited to $2-4 \mathrm{~K}$ (see Fig. 3), and cuts down the sensitivity to aerosols in the boundary layer. Moreover, the concentration of polluting particles is at its seasonal minimum, because of the absence of sources such as biomass burning. As a concluding remark on this aspect, in Denjean et al. (2016) it is shown that pollution particles have only a small influence on the optical properties of the dust plumes over the western Mediterranean, and that other mixing effects, like coating of polluting species on dust particles, have no relevant effect on their optical behaviour. Hence, in these conditions, the direct comparison between simulations and IASI observations in the thermal infrared, relying on well-characterized dimensional distributions, can be a way of validating the goodness of dust indices, and to probe the sensitivity of satellite-based, hyperspectral, infrared Earth observations to the geographical origin of aerosol. We perform a direct comparison between the spectral residuals obtained with the two sets of indices, both spectrum by spectrum, and on the day-by-day average, in order to see whether or not significant, systematic discrepancies occur.

\section{Results}

\subsection{Single spectra results}

Here we first show sample spectra with the aim to give an idea of the accuracy of the model with respect to the single spectrum simulation, and to provide a first, qualitative feedback about the difference between clear-sky calculations, those in presence of dust aerosol, and IASI spectra. Figures 6 and 7 represent two single spectra (one for 22 June and the second acquired on 3 July) among those (see Fig. 2) selected for the analysis. The two plots show the most prominent spectral signatures that affect IASI radiances; among them, the $v_{2}$ and $v_{3} \mathrm{CO}_{2}$ absorption bands, centred at 667 and $2385 \mathrm{~cm}^{-1}$, the $\mathrm{O}_{3}$ band at $1040 \mathrm{~cm}^{-1}$, and the wide $\mathrm{H}_{2} \mathrm{O} v_{2}$ absorption band centred at $1590 \mathrm{~cm}^{-1}$, and many other minor features in the three atmospheric windows $780-980 \mathrm{~cm}^{-1}$, $1070-1200 \mathrm{~cm}^{-1}$, and beyond $2440 \mathrm{~cm}^{-1}$. A more detailed focus on these regions is given in the same figures, which is important since the aerosol extinction effect is heavily manifested therein, with differences in brightness temperature units that can be as large as $5 \mathrm{~K}$ for the case of 22 June. At first glance, we can see that the radiance computed with $\sigma$ IASI-as including the dust aerosol impact reproduces fairly 

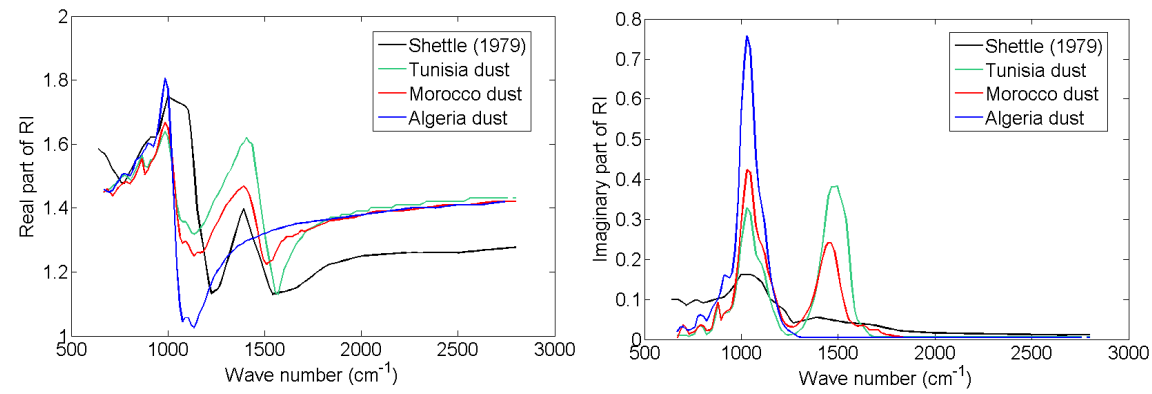

Figure 5. Complex refractive indices used as input in the radiative transfer calculations. Left plot: real part of Shettle and Fenn (1979) (black curve) and of the three indices (red, green, and blue curves) derived by Di Biagio et al. (2017); right plot: same as left, but for the imaginary part.
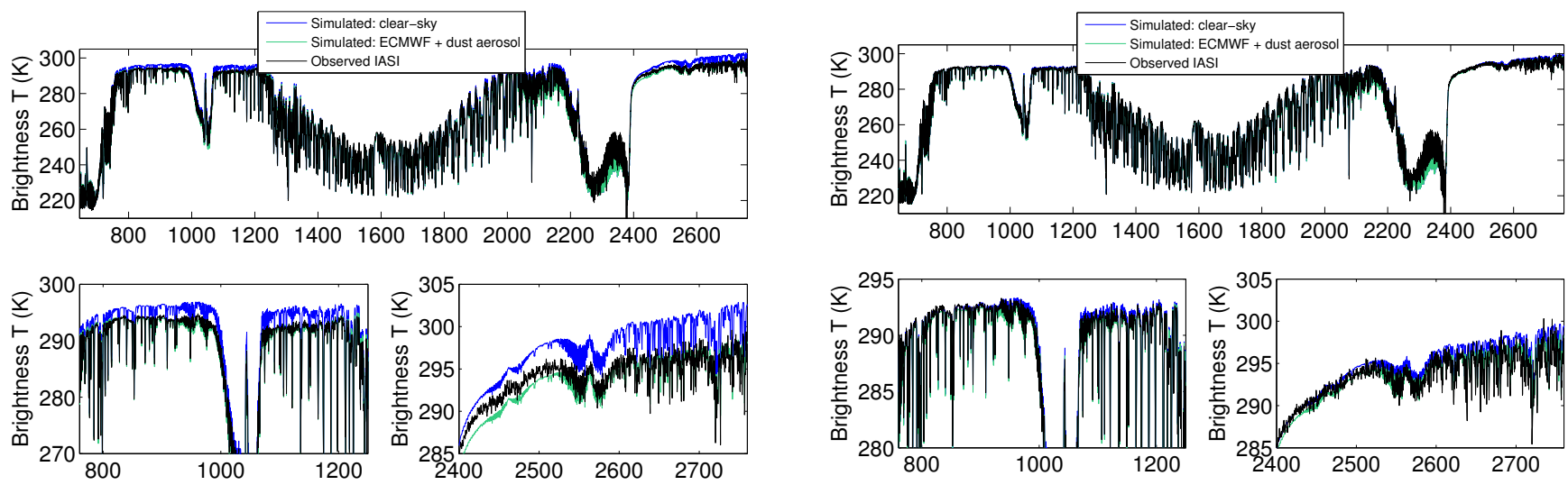

Figure 6. Sample IASI spectrum (black) acquired on 22 June (higher dust aerosol load) compared with radiative transfer simulations in absence (blue) and presence (green) of dust aerosol. Refractive indices are from Di Biagio et al. (2014).

the radiance as observed by IASI. The extinction due to the behaviour of complex refractive index at both sides of the $\mathrm{O}_{3}$ band is well manifested both in the computed and observed radiances. It is proper to point out that both the surface temperature and the water vapour columnar amount provided by ECMWF and used by the model have been slightly tuned in order to better match IASI observations, which is necessary to correct some well-known biases typical of ECMWF reanalyses, and because we do not perform any retrieval of the true state vector.

As a general remark, we observe that, in both cases, the simulated radiance is closer to that observed by IASI in the longwave atmospheric windows than in the shortwave. Part of this inconsistency is certainly due to the fact that $\sigma$-IASIas does not reproduce non-LTE effects, which is of interest especially for the $v_{3} \mathrm{CO}_{2}$ absorption band. This leads to biases that can be as large as $8 \mathrm{~K}$ in the core of the $\mathrm{CO}_{2} \nu_{3}$ band. However, since aerosol extinction effects are dominant in the atmospheric windows, it is likely that the observed residuals
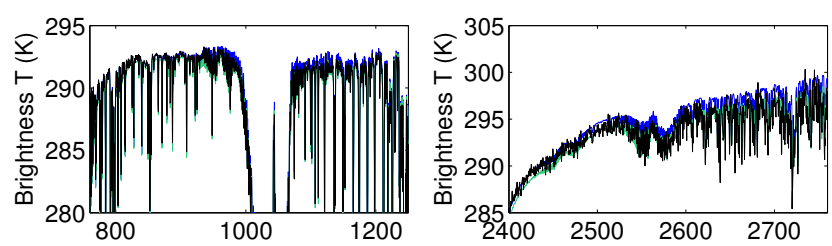

Figure 7. As Fig. 6, with a second spectrum acquired on 3 July (low aerosol load).

at wave numbers $>2400 \mathrm{~cm}^{-1}$ are due to a poor characterization of refractive indices in that spectral range.

\subsection{Residuals analysis: refractive index variability}

The conclusion expressed above is reinforced if we perform a more detailed analysis on spectral residuals on the average of the IASI soundings for each of the days we have considered. In this discussion, we examine also in detail the difference between the radiance simulated with the two sets of refractive indices cited before.

Figure 8 shows the whole, average observed and simulated spectra (with and without dust aerosol), a close-up of the spectral windows, and the differences between observed and calculated radiances computed over the 12 selected spectra for the first case (22 June). The first three plots seem to confirm what has been already observed on the single spectra, while new insights are revealed by residuals (last panel). Having not retrieved in any way atmospheric and surface parameters from spectra, some of the structures seen in the residuals are those due to biases within ECMWF analyses among them, the evident misfit of the $\mathrm{CO}_{2}$ band at 667, 720, and $750 \mathrm{~cm}^{-1}$ identified in Liuzzi et al. (2016), and related to 

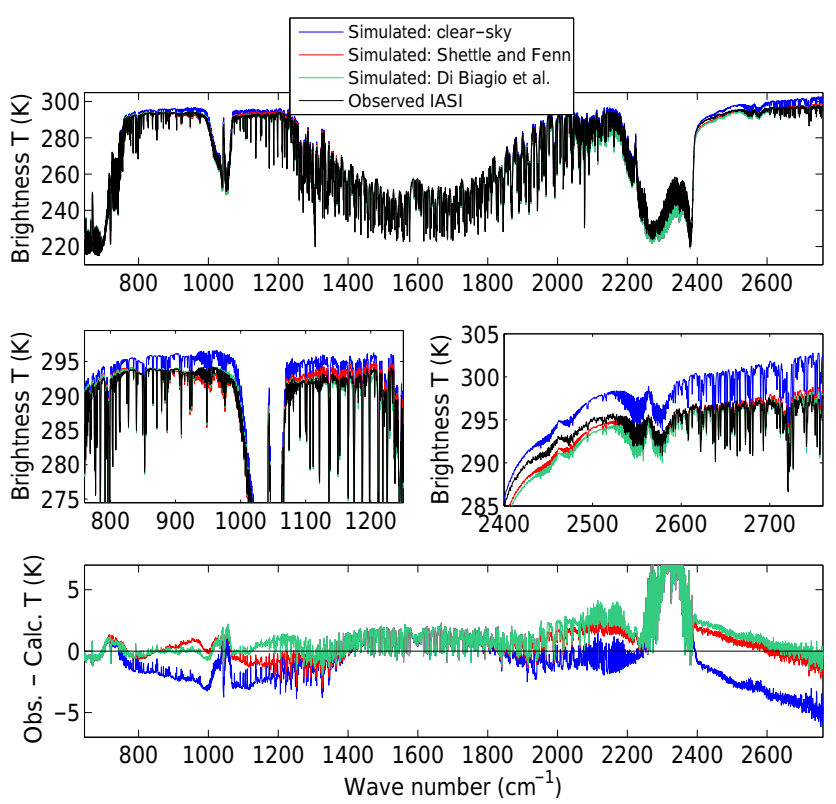

Figure 8. Top panel: IASI average spectrum (black) of the 12 soundings acquired on 22 June, compared to the average of the computed spectra: clear sky (blue), with dust aerosol, using Shettle and Fenn (1979) refractive indices (red), and Di Biagio et al. (2017) indices (green). Middle panels: close-up of the spectra in the IASI longwave (left) and shortwave (right) atmospheric windows. Bottom panel: residuals computed in the three cases.

the fact that ECMWF analyses actually tend to overestimate stratopause temperature and to underestimate the tropopause and high troposphere temperature, both by $2-4 \mathrm{~K}$. An average bias of $1 \mathrm{~K}$ is also manifested in the spectral region related to water vapour absorption, which again is related to the uncertainties typical of ECMWF water vapour profiles (10$20 \%$ ). Moreover, $\mathrm{CH}_{4}$ and $\mathrm{HDO} / \mathrm{H}_{2} \mathrm{O}$ isotopic ratio profiles are not tuned with respect to IASI observations, and this results in the residual spectral features around 1300 and beyond $2600 \mathrm{~cm}^{-1}$ (Liuzzi et al., 2016). The last major bias, due to radiative transfer limitations, is the large misfit in the $\nu_{3}$ band of $\mathrm{CO}_{2}$, caused by the already cited negligence of non-LTE effects in the code.

As far as aerosols are concerned, their average effect is to adjust the spectral slope in the atmospheric windows, reducing the difference with the observed IASI average spectrum. In fact, there are significant discrepancies between the two sets of refractive indices: if we use the indices by Shettle and Fenn (1979), they generate an inconsistency between the atmospheric windows at the two sides of the ozone band, with an evident misfit around $950 \mathrm{~cm}^{-1}$, and a continuous residual as large as $1.5 \mathrm{~K}$ in the interval $1070-1200 \mathrm{~cm}^{-1}$. Such residuals are largely suppressed in the interval $780-980 \mathrm{~cm}^{-1}$ by adopting the more recently derived indices of Di Biagio et al. (2017), while they do not solve the issues in the interval $1070-1200 \mathrm{~cm}^{-1}$. The same conclusion can be drawn for the shortwave spectral window, where the same continuous slope appears using both refractive index sets. To summarize, in this first case it seems that the choice of using refractive indices like those of Di Biagio et al. (2017), which account for the geographic source of the aerosol, solves part of the inconsistencies which are observed with a standard set of indices. In this sense, IASI data reflect the specific provenance of the observed aerosol. Nevertheless, some spurious features in the residuals still remain using both sets, suggesting that further efforts are needed to characterize the specific refractive indices in the thermal infrared.

Similar effects appear in the comparison between observations and simulations for the two other days, which are reported in Figs. 9 and 10. In these two cases, the most abundant aerosol is that coming from Tunisia. In the case of 28 June, we observe that the new indices of Di Biagio et al. suppress the slope introduced using the indices of Shettle and Fenn (1979), which is as large as $1.5 \mathrm{~K}$, and attenuate the misfit in the shortwave, while inconsistencies still hold between the two atmospheric windows at the sides of the ozone band. Analogous observations can be done in the case of 3 July, both in the longwave and in the shortwave windows. In particular, in this last case it can be seen that the newer indices partially improve the average residuals in the shortwave, reducing them below $1 \mathrm{~K}$, modifying also the slope in this spectral interval. This is a peculiarity of this last case study but, overall, the results shown so far seem to suggest that the inconsistencies observed in the shortwave can be ascribed to a still poor characterization of dust refractive indices in this spectral region.

A quantitative comparison between residuals is summarized in Table 3. We stress that the standard deviations in Table 3 are computed on spectral channels, and not on single spectra. To clarify, if $N$ is the number of spectral points (at a resolution of $15 \mathrm{~cm}^{-1}$ ) in the spectral window we are analysing, and $R\left(\sigma_{i}\right), i=\{1, \ldots, N\}$ the average, spectrally binned radiance vector, where the average is made over the $M$ spectra we consider, the standard deviation is computed as

$\left[\frac{1}{N-1} \sum_{i=1}^{N}\left(R\left(\sigma_{i}\right)-\bar{R}\right)^{2}\right]^{\frac{1}{2}}$,

where $\bar{R}$ is the average spectral residual in that particular spectral window. In this way, the standard deviation brings information about the spurious variability introduced by an incorrect characterization of the refractive index, and can be compared with IASI radiometric noise.

In the shortwave spectral window (last column), the two indices exhibit the same standard deviations, which are above the IASI noise (Serio et al., 2015) only in the case of 22 June. This shows the need to better characterize dust aerosol spectral properties in this region for aerosols coming from Algeria and Morocco, while the input indices for Tunisian aerosol give satisfactory results. In the longwave, instead, the indices 
Table 3. Summary of root mean square differences and related standard deviations computed using the two sets of refractive indices in the three selected scenarios. Data are computed averaging the residuals on a spectral grid with a sampling of $15 \mathrm{~cm}^{-1}$, the same used by $\sigma$-IASI-as to compute aerosol extinction, in order to suppress most of the variability due to gas spectral lines, retaining only the variability due to aerosol extinction.

\begin{tabular}{lllll}
\hline \multirow{2}{*}{ Ref. index } & \multicolumn{3}{c}{ RMSD \pm SD (K) } \\
\cline { 3 - 5 } & & $780-980 \mathrm{~cm}^{-1}$ & $1070-1200 \mathrm{~cm}^{-1}$ & $2440-2760 \mathrm{~cm}^{-1}$ \\
\hline \multirow{2}{*}{ 22 June } & Shettle and Fenn (1979) & $0.134 \pm 0.460$ & $0.288 \pm 0.160$ & $0.165 \pm 0.760$ \\
& Di Biagio et al. (2014) & $0.039 \pm 0.130$ & $0.161 \pm 0.380$ & $0.224 \pm 0.780$ \\
\hline \multirow{2}{*}{ 28 June } & Shettle and Fenn (1979) & $0.175 \pm 0.400$ & $0.082 \pm 0.260$ & $0.338 \pm 0.160$ \\
& Di Biagio et al. (2014) & $0.077 \pm 0.080$ & $0.225 \pm 0.220$ & $0.156 \pm 0.160$ \\
\hline \multirow{2}{*}{ 3 July } & Shettle and Fenn (1979) & $0.057 \pm 0.140$ & $0.085 \pm 0.090$ & $0.117 \pm 0.380$ \\
& Di Biagio et al. (2014) & $0.019 \pm 0.055$ & $0.185 \pm 0.130$ & $0.081 \pm 0.370$ \\
\hline \multirow{2}{*}{ IASI av. noise (K) } & 0.123 & 0.137 & 0.577 \\
\hline
\end{tabular}

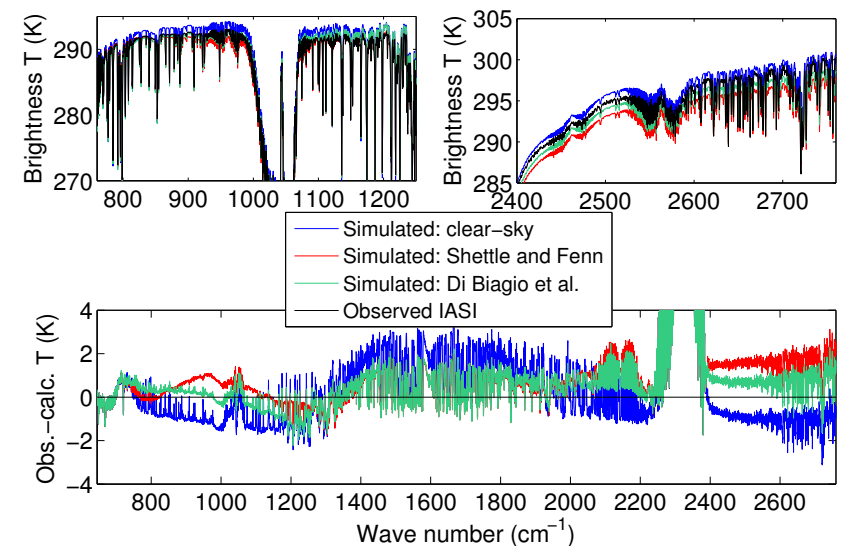

Figure 9. Top and bottom panels: same as middle and bottom panels of Fig. 8, for the case of 28 June (medium aerosol load). Average residuals are computed over 15 IASI soundings.

of Di Biagio et al. (2017) steadily reduce the average RMSD and standard deviations below the IASI average noise level in all three cases in the spectral window $780-980 \mathrm{~cm}^{-1}$. Instead, in the atmospheric window $1070-1200 \mathrm{~cm}^{-1}$, the average residual is better for these indices than those computed using the indices of Shettle and Fenn (1979) in the case of 22 June, while for the cases where the dominant aerosol is that from Tunisia, the new indices yield double average residuals, and generally larger standard deviations. To summarize, in the longwave the refractive indices for the aerosol coming from Algeria and Morocco seem to perform better than those of Shettle and Fenn (1979), which is the opposite of what we observe in the shortwave.
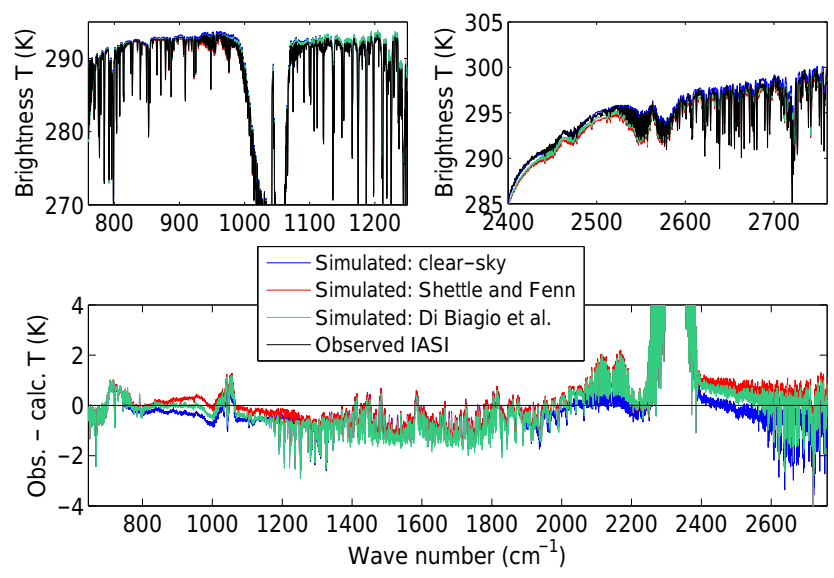

Figure 10. As Fig. 9, for the case of 3 July (low aerosol load). Average residuals are computed over 18 IASI soundings.

\subsection{Residuals analysis: dimensional distribution variability}

A more complete picture of the sensitivity of IASI data with respect to dust aerosol properties can be achieved by quantifying the effect of the dimensional distribution of particles on the observed radiance. They should be compared to the magnitude of the effects caused by the heterogeneity of refractive indices. Moreover, there is a number of studies (e.g. Tegen and Lacis, 1996; Mahowald et al., 2014) in which the relation between aerosol particle size and its radiative properties is investigated; hence this kind of analysis is necessary to assess the possibility to exploit infrared satellite data to characterize desert dust particles.

To this end, the IASI data sets of 22 and 28 June have been considered, while the data of 3 July have been discarded because of the limited radiative impact of aerosol. Simulations have been performed using the refractive indices of Di Biagio et al. (2017), and varying the average radius of the log- 


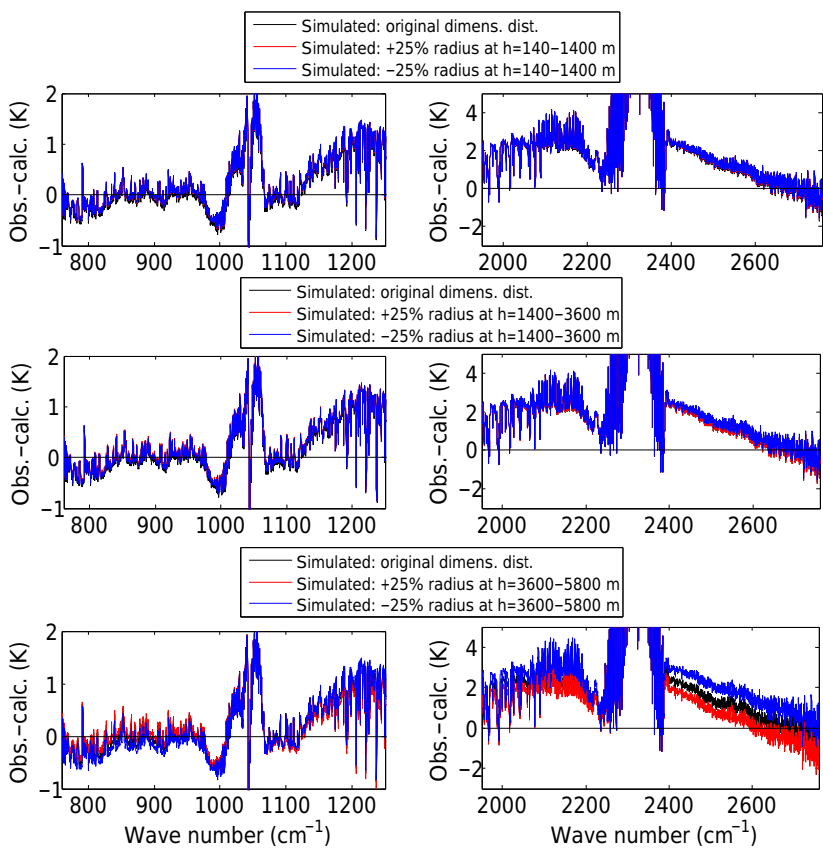

Figure 11. From the top. Left: average residuals (computed as in the previous cases) varying the average particle radii of $25 \%$ in the altitude range 140-1400 m (blue and red), compared with the residuals obtained used the radii reported in Table 2 (black, green in previous figures). Middle plot: same as top, but changing the radii in the altitude range 1400-3600 m. Bottom: same as before, but changing the radii in the interval $3600-5800 \mathrm{~m}$. Right plots: same as left, but in the spectral interval $1950-2600 \mathrm{~cm}^{-1}$.

normal distributions at different altitudes - those reported in Table 2.

Let us denote by $R$ the modified particle radius; to preserve the dust total column, we simply rescale the radius by the ratio $R / R_{0}$, and the particle concentration by $\left(R_{0} / R\right)^{3}$, where $R_{0}$ is that reported in Table 2. For this exercise, the radius has been increased and decreased by $25 \%$, hence it is $R / R_{0}=1.25$ or $R / R_{0}=0.75$.

Figure 11 reports the residuals in the same three spectral windows as before, computed varying the average radii in each altitude interval for the case of 22 June. Here it is nicely evidenced that a change of $25 \%$ of the average dimension of dust particles in the lower layers, below $1400 \mathrm{~m}$, yields a change in the observed radiance which is confined below IASI radiometric noise $(<0.1 \mathrm{~K}$ throughout all the spectral windows). A similar conclusion can be drawn if the particle radius is modified in the altitude range $1400-3600 \mathrm{~m}$. Instead, simulations show that the dimensional properties of the upper layers of desert dust have a major influence on the observed radiance. In this case, we can see that an increase/decrease of $25 \%$ of particle average radii is reflected in a $0.1 \mathrm{~K}$ radiance decrease/increase in the spectral windows in the longwave, and a $0.5 \mathrm{~K}$ radiance decrease/increase in the shortwave. This is consistent with the fact that, in the

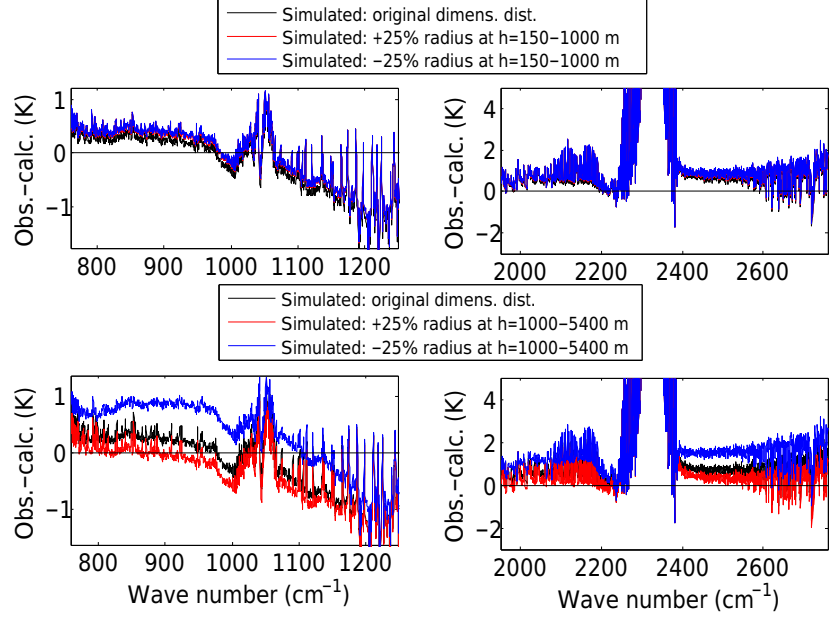

Figure 12. As Fig. 11, but for the case of 28 June.

shortwave, aerosol extinction is essentially due to scattering efficiency, which increases with respect to absorption efficiency as particles become smaller.

Similar effects are observed in the case of 28 June (see Fig. 12): again, a change of $25 \%$ of the average particle size in the lower atmospheric layers does not produce any net observable effect above IASI radiometric noise, neither in the longwave, nor in the shortwave portion of the IASI spectrum. The same change applied to dust particles in the altitude range 1000-5400 $\mathrm{m}$ conveys changes in the observed radiance which are around $0.7 \mathrm{~K}$ in the shortwave windows, and up to $0.7 \mathrm{~K}$ in the longwave. In this case the impact on the observed radiance is greater than in the previous case, since the thickness of the aerosol distribution in which we modify the particle average size is greater. However, in both cases there is an inconsistency between the residuals' behaviour in the shortwave atmospheric windows, and that in the longwave, particularly in the interval $1070-1200 \mathrm{~cm}^{-1}$. These effects are well above the IASI radiometric noise within the selected atmospheric windows, and demonstrate, again, the need of a better characterization of the radiative behaviour of desert dust aerosols, especially in the shortwave portion of IASI spectrum, where major residuals are found.

Regarding the radiative transfer scheme, taking into account that the shortwave slope decreases with the aerosol load, we can argue that the multiple scattering scheme adopted by $\sigma$-IASI-as is actually effective in reproducing the observed radiance, at least with the aerosol loads we have observed in these cases. In the longwave atmospheric windows, where scattering effects are of second order with respect to pure absorption, simulations demonstrate that IASI is capable to capture salient characteristics of the desert dust well above the radiometric noise average level. In this case, the "absorption approach" adopted by the radiative transfer model is effective. 


\section{Conclusions}

In this work we have provided an in-depth description of the new $\sigma$-IASI-as radiative transfer model, and used it to probe the goodness of the characterization of the microphysical properties and refractive indices of desert dust aerosol over Lampedusa in the context of the ChArMEx experiment, in three cases with a variable aerosol load.

The radiative transfer model we have presented is based on a pseudo-monochromatic approach as far as gas optical depth calculation is concerned, while it exploits ab initio Mie calculations to calculate aerosol extinction. This makes the model extremely feasible with respect to the aerosol properties, as has been shown in this paper. Moreover, the model has not been tailored to any particular instrument, thus it is immediately available, in particular, for the next generation of hyper-spectral sensors (e.g. IASI-NG, MTG-IRS) whose operativity is scheduled in the next 10 years.

The calculations we have performed have exploited the characterization of dimensional distributions of desert dust particles over Lampedusa performed by dedicated instruments. The high level of detail of these observations has enabled us to assess, in particular, the effectiveness of refractive indices used to model desert dust aerosol extinction, by comparing different models.

Overall, we find that the dimensional distributions derived from ChArMEx observations show a fair consistency between observations and calculations in the thermal infrared wavelengths. In contrast, the discrepancies are significant in the shortwave portion of the IASI spectrum where, in any case, also other major effects occur (e.g. non-LTE). The discrepancies observed between IASI radiances and calculated spectra in this region evidence the need to better characterize dust extinction in the mid-near infrared (as already stated in other contexts, e.g. Carboni et al., 2012), especially in cases where the observed aerosol has heterogeneous geographical source. In the thermal infrared, instead, the observed residuals are generally better, and compatible with the uncertainties that affect the other radiative transfer input data (ECMWF atmospheric profiles and surface properties). However, better consistency has to be achieved between different spectral intervals.

This validation study is a further step toward the possibility to retrieve directly from IASI radiances the microphysical properties of clouds and aerosols, namely their vertical distribution and/or particle dimensional distributions, thanks to the fact that the radiative transfer model we have elaborated has the ability to compute analytical or semi-analytical Jacobians of the radiance also with respect to particle concentration.

\section{Data availability}

All the IASI spectra, radiative transfer simulations, and input atmospheric profiles of temperature, water vapour and ozone are available at the following URL: https://www.researchgate.net/publication/313847146_

Supplementary_data_to_the_paper_Consistency_of_ dimensional_distributions_and_refractive_indices_of_ desert_dust_measured_over_Lampedusa_with_IASI_ radiances_Atmos_Meas_Tech_in_press (Liuzzi, 2017).

Competing interests. The authors declare that they have no conflict of interest.

Acknowledgements. IASI was developed and built under the responsibility of CNES. It is flown on board the MetOp satellites as part of the EUMETSAT Polar System. The IASI L1 data are received through the EUMETCast near-real-time data distribution service. External calibration IASI L1 data and corresponding engineering data are provided by the IASI Technical Expertise Centre at CNES. C. Di Biagio was supported by the CNRS via the Labex L-IPSL, which is funded by the ANR (grant no. ANR-10-LABX-0018).

Edited by: X. Querol.

Reviewed by: two anonymous referees

\section{References}

Amato, U., Masiello, G., Serio, C., and Viggiano, M.: The $\sigma$ IASI code for the calculation of infrared atmospheric radiance and its derivatives, Environ. Modell. Softw., 17, 651-667, doi:10.1016/S1364-8152(02)00027-0, 2002.

Amato, U., Lavanant, L., Liuzzi, G., Masiello, G., Serio, C., Stuhlmann, R., and Tjemkes, S. A.: Cloud mask via cumulative discriminant analysis applied to satellite infrared observations: scientific basis and initial evaluation, Atmos. Meas. Tech., 7, 3355-3372, doi:10.5194/amt-7-3355-2014, 2014.

Anderson, G. P., Clough, S. A., Kneizys, F. X., Chetwynd, J. H., and Shettle, E. P.: AFGL atmospheric constituent profiles (0$120 \mathrm{~km})$, Geophysics Laboratory, Hanscom Air Force Base, USA, 1986.

Banks, J. R., Brindley, H. E., Flamant, C., Garay, M. J., Hsu, N. C., Kalashnikova, O. V., Klüser, L., and Sayer, A. M.: Intercomparison of satellite dust retrieval products over the west African Sahara during the Fennec campaign in June 2011, Remote Sens. Environ., 136, 99-116, doi:10.1016/j.rse.2013.05.003, 2013.

Berthier, S., Chazette, P., Couvert, P., Pelon, J., Dulac, F., Thieuleux, F., Moulin, C., and Pain, T.: Desert dust aerosol columnar properties over ocean and continental Africa from Lidar in-Space Technology Experiment (LITE) and Meteosat synergy, J. Geophys. Res., 111, D21202, doi:10.1029/2005JD006999, 2006.

Bohren, C. F. and Huffmann, D. R.: Absorption and scattering of light by small particles, Wiley-Interscience, New York, NY, USA, 2000. 
Carboni, E., Thomas, G. E., Sayer, A. M., Siddans, R., Poulsen, C. A., Grainger, R. G., Ahn, C., Antoine, D., Bevan, S., Braak, R., Brindley, H., DeSouza-Machado, S., Deuzé, J. L., Diner, D., Ducos, F., Grey, W., Hsu, C., Kalashnikova, O. V., Kahn, R., North, P. R. J., Salustro, C., Smith, A., Tanré, D., Torres, O., and Veihelmann, B.: Intercomparison of desert dust optical depth from satellite measurements, Atmos. Meas. Tech., 5, 1973-2002, doi:10.5194/amt-5-1973-2012, 2012.

Chance, K. and Kurucz, R. L.: An improved high-resolution solar reference spectrum for Earth's atmosphere measurements in the ultraviolet, visible, and near infrared, J. Quant. Spectrosc. Radiat. Transfer, 111, 1289-1295, doi:10.1016/j.jqsrt.2010.01.036, 2010.

Chanine, M. T.: Remote sounding of cloudy atmospheres. I. The single cloud layer, J. Atmos. Sci., 31, 233-243, doi:10.1175/1520-0469(1974)031<0233:RSOCAI >2.0.CO;2, 1974.

Chen, G., Ziemba, L. D., Chu, D. A., Thornhill, K. L., Schuster, G. L., Winstead, E. L., Diskin, G. S., Ferrare, R. A., Burton, S. P., Ismail, S., Kooi, S. A., Omar, A. H., Slusher, D. L., Kleb, M. M., Reid, J. S., Twohy, C. H., Zhang, H., and Anderson, B. E.: Observations of Saharan dust microphysical and optical properties from the Eastern Atlantic during NAMMA airborne field campaign, Atmos. Chem. Phys., 11, 723-740, doi:10.5194/acp11-723-2011, 2011.

Chou, M.-D., Lee, K.-T., Tsay, S.-C., and Fu, Q.: Parameterization for Cloud Longwave Scattering for Use in Atmospheric Models, J. Climate, 12, 159-169, doi:10.1175/1520-0442-12.1.159, 1999.

Clarisse, L., Coheur, P.-F., Prata, F., Hadji-Lazaro, J., Hurtmans, D., and Clerbaux, C.: A unified approach to infrared aerosol remote sensing and type specification, Atmos. Chem. Phys., 13, 2195 2221, doi:10.5194/acp-13-2195-2013, 2013.

Clough, S. A., Shephard, M. W., Mlawer, E. J., Delamere, J. S., Iacono, M. J., Cady-Pereira, K., Boukabara, S., and Brown, P. D.: Atmospheric radiative transfer modeling: a summary of the AER codes, Short Communication, J. Quant. Spectrosc. Radiat. Transfer, 91, 233-244, doi:10.1016/j.jqsrt.2004.05.058, 2005.

Cuesta, J., Eremenko, M., Flamant, C., Dufour, G., Laurent, B., Bergametti, G., Höpfner, M., Orphal, J., and Zhou, D.: Satellite observation of the $3 \mathrm{D}$ distribution of dust plumes from IASI throughout a major desert dust outbreak across East Asia in March 2008, J. Geophys. Res., 120, 7099-7127, doi:10.1002/2014JD022406, 2015.

Denjean, C., Cassola, F., Mazzino, A., Triquet, S., Chevaillier, S., Grand, N., Bourrianne, T., Momboisse, G., Sellegri, K., Schwarzenbock, A., Freney, E., Mallet, M., and Formenti, P.: Size distribution and optical properties of mineral dust aerosols transported in the western Mediterranean, Atmos. Chem. Phys., 16, 1081-1104, doi:10.5194/acp-16-1081-2016, 2016.

Di Biagio, C., di Sarra, A., and Meloni, D.: Large atmospheric shortwave radiative forcing by Mediterranean aerosols derived from simultaneous ground-based and spaceborne observations and dependence on the aerosol type and single scattering albedo, J. Geophys. Res., 115, D10209, doi:10.1029/2009JD012697, 2010.

Di Biagio, C., Formenti, P., Styler, S. A. Pangui, E., and Doussin, J.F.: Laboratory chamber measurements of the longwave extinction spectra and complex refractive indices of African and
Asian mineral dusts, Geophys. Res. Lett., 41, 6289-6297, doi:10.1002/2014GL060213, 2014.

Di Biagio, C., Formenti, P., Balkanski, Y., Caponi, L., Cazaunau, M., Pangui, E., Journet, E., Nowak, S., Caquineau, S., Andreae, M. O., Kandler, K., Saeed, T., Piketh, S., Seibert, D., Williams, E., and Doussin, J.-F.: Global scale variability of the mineral dust long-wave refractive index: a new dataset of in situ measurements for climate modeling and remote sensing, Atmos. Chem. Phys., 17, 1901-1929, doi:10.5194/acp-17-1901-2017, 2017.

di Sarra, A., Pace, G., Meloni, D., De Silvestri, L., Piacentino, S., and Monteleone, F.: Surface shortwave radiative forcing of different aerosol types in the central Mediterranean, Geophys. Res. Lett., 35, L02714, doi:10.1029/2007GL032395, 2008.

di Sarra, A., Di Biagio, C., Meloni, D., Monteleone, F., Pace, G., Pugnaghi, S., and Sferlazzo, D.: Shortwave and longwave radiative effects of the intense Saharan dust event of 25-26 March 2010 at Lampedusa (Mediterranean Sea), J. Geophys. Res., 116, D23209, doi:10.1029/2011JD016238, 2011.

Elsasser, W. M.: Heat Transfer by Infrared Radiation in the Atmosphere, Harvard Meteorol. Studies, 6, Harvard Univ. Press, Cambridge, MA, 1942.

Faijan, F., Lavanant, L., and Rabier, F.: Towards the use of cloud microphysical properties to simulate IASI spectra in an operational context, J. Geophys. Res., 117, D22205, doi:10.1029/2012JD017962, 2012.

Henyey, L. G., and Greenstein, J. L.: Diffuse radiation in the Galaxy, Astrophysical Journal, 93, 70-83, doi:10.1086/144246, 1941.

Hess, M., Koepke, P., and Schult, I.: Optical Properties of Aerosols and Clouds: The Software Package OPAC, B. Am. Meteorol. Soc., 79, 831-844, doi:10.1175/15200477(1998)079<0831:OPOAAC>2.0.CO;2, 1998.

Hilton, F., Armante, R., August, T., Barnet, C., Bouchard, A., Camy-Peyret, C., Capelle, V., Clarisse, L., Clerbaux, C., Coheur, P. F., Collard, A., Crevoisier, C., Dufour, G., Edwards, D., Faijan, F., Fourrié, N., Gambacorta, A., Goldberg, M., Guidard, V., Hurtmans, D., Illingworth, S., JacquinetHusson, N., Kerzenmacher, T., Klaes, D., Lavanant, L., Masiello, G., Matricardi, M., McNally, A., Newman, S., Pavelin, E., Payan, S., Péquignot, E., Peyridieu, S., Phulpin, T., Remedios, J., Schlüssel, P., Serio, C., Strow, L., Stubenrauch, C., Taylor, J., Tobin, D., Wolf, W., and Zhou, D.: Hyperspectral Earth Observation from IASI: five years of accomplishments, B. Am. Meteorol. Soc., 93, 347-370, doi:10.1175/BAMS-D-1100027.1, 2012.

Hollweg, H.-D., Bakan, S., and Taylor, J. P.: Is the aerosol emission detectable in the thermal infrared, J. Geophys. Res., 111, D15202, doi:10.1029/2005JD006432, 2006.

Klüser, L., Kleiber, P., Holzer-Popp, T., and Grassian, V. H.: Desert dust observation from space - Application of measured mineral component infrared extinction spectra, Atmos. Environ., 54, 419-427, doi:10.1016/j.atmosenv.2012.02.011, 2012.

Klüser, L., Banks, J. R., Martynenko, D., Bergemann, C., Brindley, H. E., and Holzer-Popp, T.: Information content of spaceborne hyperspectral infrared observations with respect to mineral dust properties, Remote Sens. Environ., 156, 294-309, doi:10.1016/j.rse.2014.09.036, 2015.

Liuzzi, G., Masiello, G., Serio, C., Palchetti, L., and Bianchini, G.: Validation of $\mathrm{H}_{2} \mathrm{O}$ continuum absorption models in the wave number range $180-600 \mathrm{~cm}^{-1}$ with atmospheric emitted spec- 
tral radiance measured at the Antarctica Dome-C site, Optics Express, 22, 16784-16801, doi:10.1364/OE.22.016784, 2014.

Liuzzi, G., Masiello, G., Serio, C., Venafra, S., and CamyPeyret, C.: Physical inversion of the full IASI spectra: Assessment of atmospheric parameters retrievals, consistency of spectroscopy and forward modelling, J. Quant. Spectrosc. Rad. Transfer, 182, 128-157, doi:10.1016/j.jqsrt.2016.05.022, 2016.

Liuzzi, G.: Supplementary data to the paper "Consistency of dimensional distributions and refractive indices of desert dust measured over Lampedusa with IASI radiances", available at: https://www. researchgate.net/publication/313847146_Supplementary_data_ to_the_paper_Consistency_of_dimensional_distributions_and_ refractive_indices_of_desert_dust_measured_over_Lampedusa_ with_IASI_radiances_Atmos_Meas_Tech_in_press, 2017.

Mahowald, N., Albani, S., Kok, J. F., Engelstaeder, S., Scanza, R., Ward, D. S., and Flanner, M. G.: The size distribution of desert dust aerosols and its impact on the Earth system, Aeolian Research, 15, 53-71, doi:10.1016/j.aeolia.2013.09.002, 2014.

Mallet, M., Dulac, F., Formenti, P., Nabat, P., Sciare, J., Roberts, G., Pelon, J., Ancellet, G., Tanré, D., Parol, F., Denjean, C., Brogniez, G., di Sarra, A., Alados-Arboledas, L., Arndt, J., Auriol, F., Blarel, L., Bourrianne, T., Chazette, P., Chevaillier, S., Claeys, M., D’Anna, B., Derimian, Y., Desboeufs, K., Di Iorio, T., Doussin, J.-F., Durand, P., Féron, A., Freney, E., Gaimoz, C., Goloub, P., Gómez-Amo, J. L., Granados-Muñoz, M. J., Grand, N., Hamonou, E., Jankowiak, I., Jeannot, M., Léon, J.-F., Maillé, M., Mailler, S., Meloni, D., Menut, L., Momboisse, G., Nicolas, J., Podvin, T., Pont, V., Rea, G., Renard, J.-B., Roblou, L., Schepanski, K., Schwarzenboeck, A., Sellegri, K., Sicard, M., Solmon, F., Somot, S., Torres, B., Totems, J., Triquet, S., Verdier, N., Verwaerde, C., Waquet, F., Wenger, J., and Zapf, P.: Overview of the Chemistry-Aerosol Mediterranean Experiment/Aerosol Direct Radiative Forcing on the Mediterranean Climate (ChArMEx/ADRIMED) summer 2013 campaign, Atmos. Chem. Phys., 16, 455-504, doi:10.5194/acp-16-455-2016, 2016.

Masiello, G., and Serio, C.: An effective water vapor selfbroadening scheme for look-up-table-based radiative transfer, Proc. SPIE, 4882, 52-61, doi:10.1117/12.462580, 2003.

Masiello, G., Serio, C., Carissimo, A., Grieco, G., and Matricardi, M.: Application of $\varphi$-IASI to IASI: retrieval products evaluation and radiative transfer consistency, Atmos. Chem. Phys., 9, 87718783, doi:10.5194/acp-9-8771-2009, 2009.

Masiello, G. and Serio, C.: Simultaneous physical retrieval of surface emissivity spectrum and atmospheric parameters from infrared atmospheric sounder interferometer spectral radiances, Appl. Optics, 52, 2428-2446, doi:10.1364/AO.52.002428, 2013.

Massie, S. T., and Hervig, M.: HITRAN 2012 refractive indices, J. Quant. Spectrosc. Radiat. Transfer, 130, 373-380, doi:10.1016/j.jqsrt.2013.06.022, 2013.

Masuda, K., Takashima, T., and Takayama, Y.: Emissivity of pure and sea waters for the model sea surface in the infrared window regions, Remote Sens. Environ., 24, 313-329, doi:10.1016/00344257(88)90032-6, 1988.

Meloni, D., Junkermann, W., di Sarra, A., Cacciani, M., De Silvestri, L., Di Iorio, T., Estellés, V., Gómez-Amo, J. L., Pace, G., and Sferlazzo, D. M.: Altitude-resolved shortwave and longwave radiative effects of desert dust in the Mediterranean during the GAMARF campaign: indications of a net daily cool- ing in the dust layer, J. Geophys. Res., 120, 3386-3407, doi:10.1002/2014JD022312, 2015.

Mlawer, E. J., Payne, V. H., Moncet, J.-L., Delamere, J. S., Alvarado, M. J., and Tobin, D. D.: Development and recent evaluation of the MT_CKD model of continuum absorption, Phil. Trans. R. Soc. A, 370, 1-37, doi:10.1098/rsta.2011.0295, 2012.

Pace, G., Meloni, D., and di Sarra, A.: Forest fire aerosol over the Mediterranean basin during summer 2003, J. Geophys. Res., 110, D21202, doi:10.1029/2005JD005986, 2005.

Pace, G., di Sarra, A., Meloni, D., Piacentino, S., and Chamard, P.: Aerosol optical properties at Lampedusa (Central Mediterranean). 1. Influence of transport and identification of different aerosol types, Atmos. Chem. Phys., 6, 697-713, doi:10.5194/acp-6-697-2006, 2006.

Peyridieu, S., Chédin, A., Capelle, V., Tsamalis, C., Pierangelo, C., Armante, R., Crevoisier, C., Crépeau, L., Siméon, M., Ducos, F., and Scott, N. A.: Characterisation of dust aerosols in the infrared from IASI and comparison with PARASOL, MODIS, MISR, CALIOP, and AERONET observations, Atmos. Chem. Phys., 13, 6065-6082, doi:10.5194/acp-13-6065-2013, 2013.

Prata, A. J. and Prata, A. T.: Eyjafjallajökull volcanic ash concentrations determined using Spin Enhanced Visible and Infrared Imager measurements, J. Geophys. Res., 117, D00U23, doi:10.1029/2011JD016800, 2012.

Rothman, L. S., Gordon, I. E., Babikov, Y., Barbe, A., Chris Benner, D., Bernath, P. F., Birk, M., Bizzocchi, L., Boudon, V., Brown, L. R., Campargue, A., Chance, K., Cohen, E. A., Coudert, L. H., Devi, V. M., Drouin, B. J., Fayt, A., Flaud, J.M., Gamache, R. R., Harrison, J. J., Hartmann, J.-M., Hill, C., Hodges, J. T., Jacquemart, D., Jolly, A., Lamouroux, J., Le Roy, R. J., Li, G., Long, D. A., Lyulin, O. M., Mackie, C. J., Massie, S. T., Mikhailenko, S., Müller, H. S. P., Naumenko, O. V., Nikitin, A. V., Orphal, J., Perevalov, V., Perrin, A., Polovtseva, E. R., Richard, C., Smith, M. A. H., Starikova, E., Sung, K., Tashkun, S., Tennyson, J., Toon, G. C., Tyuterev, V. G., and Wagner, G.: The HITRAN2012 molecular spectroscopic database, J. Quant. Spectrosc. Radiat. Transfer, 130, 4-50, doi:10.1016/j.jqsrt.2013.07.002, 2013.

Saunders, R., Hocking, J., Rundle, D., Rayer, P., Matricardi, M., Geer, A., Lupu, C., Brunel, P., and Vidot, J.: RTTOV-11 Science and Validation Report, NWP/SAF Technical Document $n$. NWPSAF-MO-TV-032, 2013.

Sellitto, P., di Sarra, A., Corradini, S., Boichu, M., Herbin, H., Dubuisson, P., Sèze, G., Meloni, D., Monteleone, F., Merucci, L., Rusalem, J., Salerno, G., Briole, P., and Legras, B.: Synergistic use of Lagrangian dispersion and radiative transfer modelling with satellite and surface remote sensing measurements for the investigation of volcanic plumes: the Mount Etna eruption of 25-27 October 2013, Atmos. Chem. Phys., 16, 6841-6861, doi:10.5194/acp-16-6841-2016, 2016.

Sellitto, P. and Legras, B.: Sensitivity of thermal infrared nadir instruments to the chemical and microphysical properties of UTLS secondary sulfate aerosols, Atmos. Meas. Tech., 9, 115-132, doi:10.5194/amt-9-115-2016, 2016.

Serio, C., Standfuss, C., Masiello, G., Liuzzi, G., Dufour, E., Tournier, B., Stuhlmann, R., Tjemkes, S., and Antonelli, P.: Infrared Atmospheric Sounder Interferometer radiometric noise assessment from spectral residuals, Appl. Opt., 54, 5924-5936, doi:10.1364/AO.54.005924, 2015. 
Shettle, E. P., and Fenn, R. W.: Models for the Aerosols of the Lower Atmosphere and the Effects of Humidity Variations on Their Optical Properties, Geophysics Laboratory, Hanscom Air Force Base, USA, 1979.

Smith, A. J. A. and Grainger, R. G.: Does variation in mineral composition alter the short-wave light scattering properties of desert dust aerosol?, J. Quant. Spectrosc. Rad. Trans., 133, 235-243, doi:10.1016/j.jqsrt.2013.08.005, 2014.

Stamnes, K., Tsay, S. C., Wiscombe, W., and Jayaweera, K.: Numerically stable algorithm for discrete-ordinate-method radiative transfer in multiple scattering and emitting layered media, Appl. Opt., 27, 2502-2509, doi:10.1364/AO.27.002502, 1988.
Tegen, I. and Lacis, A. A.: Modeling of particle size distribution and its influence on the radiative properties of mineral dust aerosol, J. Geophys. Res., 101, 19237-19244, 1996.

Vandenbussche, S., Kochenova, S., Vandaele, A. C., Kumps, N., and De Mazière, M.: Retrieval of desert dust aerosol vertical profiles from IASI measurements in the TIR atmospheric window, Atmos. Meas. Tech., 6, 2577-2591, doi:10.5194/amt-6-2577-2013, 2013.

Warren, S. G.: Optical constants of ice from the ultraviolet to the microwave, Appl. Opt., 23, 1206-1225, doi:10.1364/AO.23.001206, 1984.

WDCGG W, WMO, World Data Centre for Greenhouse Gases (WDCGG) data summary, vol. 39, 115 pp., 2015. 